\title{
GIS-Based Multi-Criteria Approach for Flood Vulnerability Assessment and Mapping in District Shangla: Khyber Pakhtunkhwa, Pakistan
}

\author{
Muhammad Hussain $\left.{ }^{1}{ }^{(}\right)$, Muhammad Tayyab ${ }^{1}{ }^{(0)}$, Jiquan Zhang ${ }^{1,2,3, *(\mathbb{D}}$, Ashfaq Ahmad Shah ${ }^{4}$, Kashif Ullah ${ }^{1,5}{ }^{(}$, \\ Ummer Mehmood ${ }^{1}$ and Bazel Al-Shaibah ${ }^{1}$
}

check for updates

Citation: Hussain, M.; Tayyab, M.; Zhang, J.; Shah, A.A.; Ullah, K.; Mehmood, U.; Al-Shaibah, B. GIS-Based Multi-Criteria Approach for Flood Vulnerability Assessment and Mapping in District Shangla: Khyber Pakhtunkhwa, Pakistan. Sustainability 2021, 13, 3126. https://doi.org/10.3390/su13063126

Academic Editor: Fabio Carlucci

Received: 20 February 2021

Accepted: 5 March 2021

Published: 12 March 2021

Publisher's Note: MDPI stays neutral with regard to jurisdictional claims in published maps and institutional affiliations.

Copyright: (c) 2021 by the authors. Licensee MDPI, Basel, Switzerland. This article is an open access article distributed under the terms and conditions of the Creative Commons Attribution (CC BY) license (https:/ / creativecommons.org/licenses/by/ $4.0 /)$.
1 Institute of Natural Disaster Research, School of Environment, Northeast Normal University, Changchun 130024, China; huse149@nenu.edu.cn (M.H.); Tayyabfarooqicdpm@gmail.com (M.T.); kashifkhan742@yahoo.com (K.U.); mehmoodummer90@gmail.com (U.M.); alshaibah123@gmail.com (B.A.-S.)

2 Key Laboratory for Vegetation Ecology, Ministry of Education, Changchun 130024, China

3 State Environmental Protection Key Laboratory of Wetland Ecology and Vegetation Restoration, Northeast Normal University, Changchun 130024, China

4 Center on Forecast and Evaluation of Meteorological Disasters (CIC-FEMD), School of Management Science and Engineering, Ministry of Education \& Collaborative Innovation, Nanjing University of Information Science and Technology, Nanjing 210094, China; shahaa@cau.edu.cn

5 Institute of Geophysics and Geomatics, China University of Geosciences, Wuhan 430074, China

* Correspondence: zhangjq022@nenu.edu.cn; Tel.: +86-135-9608-6467; Fax: +86-431-8916-5624

\begin{abstract}
Floods are considered one of the world's most overwhelming hydro meteorological disasters, which cause tremendous environmental and socioeconomic damages in a developing country such as Pakistan. In this study, we use a Geographic information system (GIS)-based multi-criteria approach to access detailed flood vulnerability in the District Shangla by incorporating the physical, socioeconomic vulnerabilities, and coping capacity. In the first step, 21 essential criteria were chosen under three vulnerability components. To support the analytical hierarchy process (AHP), the used criteria were transformed, weighted, and standardized into spatial thematic layers. Then a weighted overlay technique was used to build an individual map of vulnerability components. Finally, the integrated vulnerability map has been generated from the individual maps and spatial dimensions of vulnerability levels have been identified successfully. The results demonstrated that $25 \%$ of the western-middle area to the northern part of the study area comprises high to very high vulnerability because of the proximity to waterways, high precipitation, elevation, and other socioeconomic factors. Although, by integrating the coping capacity, the western-central and northern parts of the study area comprising from high to very high vulnerability. The coping capacities of the central and eastern areas are higher as compared to the northern and southern parts of the study area because of the numerous flood shelters and health complexes. A qualitative approach from the field validated the results of this study. This study's outcomes would help disaster managers, decision makers, and local administration to quantify the spatial vulnerability of flood and establish successful mitigation plans and strategies for flood risk assessment in the study area.
\end{abstract}

Keywords: geography information system; flood vulnerability; remote sensing; analytical hierarchy process (AHP); Pakistan

\section{Introduction}

Floods are considered one of the most catastrophic hydro meteorological disasters. Such catastrophes frequently triggering enormous monetary and environmental destruction and deaths [1]. About 2.3 billion inhabitants have been affected, and 157,000 lost their lives because of floods between the year 1995-2015 as estimated by the United Nations $[2,3]$. Over the past three decades of the 20th century, floods have caused nearly USD 386 billion in economic loss worldwide. The 2013 Inter Panel on Climate Change (IPCC) 
suggests that a significant proportion of the planet indicated progression in unexpected catastrophes, including droughts, severe temperatures, and average precipitations of varying magnitude [4,5]. Countries such as China, Bangladesh, Nepal, India, and Pakistan have experienced devastating floods in the last three decades [6,7]. Several recent research estimates predict that the impact and severity of flood events would increase substantially in future climate scenarios [8-16]. In addition to that, the flood risks would be exacerbated by more factors like swift urbanization [17], population growth, and economic development [1]. As a result, residents, along with their properties and the environment, would in the future be constantly at risk [18].

The assessment of vulnerability to climate change and extreme events such as floods is important to support risk mitigation and sustainable adaptation strategies [19]. In disaster-sensitive countries like Pakistan, disaster management focuses primarily on disaster assistance, crisis response, and recovery. Several studies have shown that paradigm changes from catastrophe assistance, and come back to disaster risk and liability diminution $[20,21]$. Deriving spatially consistent information on vulnerability indicators can help to evaluate and map the various scope of vulnerability across space and time to establish effective mitigation strategies [1]. Vulnerability assessment and mapping would provide a clear picture of the ground reality and display the degree to which population; capital, assets, and location are likely to be impacted by the hazard [22,23]. The development of appropriate vulnerability indices, indicators, and their integration is vital for flood vulnerability assessment in terms of achieving a real vulnerability scenario [24-26]. The provision of data and mapping information on various components of vulnerability, such as physical, coping capacity, and socioeconomic vulnerability might be used by legislators for successful administrative strategies targeting reductions as well as anticipatory maneuvers $[7,27,28]$. Flood hazard management and mitigation strategies play a crucial role in the sustainability and growth of the physical and socioeconomic climate of the country or region [21,29]. The vulnerability assessment can, therefore, lead to mitigate the flood impacts on the environment, property, and community.

In recent decades, the flood intensity and effects have resulted in a variety of studies and approaches in various countries, such as the USA [16], Slovakia [30], India [31], and Germany [32]. The flood vulnerability assessment was intensified by modifying different parameters, indexes, and indicators, as shown by the GIS space performance platform [33-35]. Vulnerability mapping has been a significant concern of global environmental sustainability and research communities in recent decades [23,34,36]. A comprehensive flood vulnerability assessment in broad-based techniques is complex due to its ambiguous concepts of vulnerability. However, the specific variables according to availability of the data that capture the necessary and decisive factor aggregation, scale which reflects and find out accurate vulnerability information is important $[17,19]$. The credibility of vulnerability is boosted by choosing the appropriate variables for each vulnerability components [37]. It is pertinent to remember that absolute flood protection is not possible, although the best possible flood mitigation plan can be implemented with the help of vulnerability assessment of an area $[38,39]$. The maps created from vulnerability evaluation could be utilized by disaster managers for constructive administration plans aiming for disaster reduction and preventive measures. According to UNISDR, 2019 [40] the natural hazards and vulnerability mapping is important to step towards the reduction of disaster effects. Several models, hypotheses, and modelling tactics have been developed to assess the vulnerabilities of disasters, but an inclusive flood pattern is unique in literature, as most of the current studies are based on limited regional criteria [22,29,41].

In the vulnerability analysis, the main subject in the target field is the selection of the appropriate variables [41]. Vulnerability is usually focused on the social, physical, economic, and political aspects which might lead an individual, community, or institution to a frantic hazard and threat acquaintance [19]. Distinctions in the segment, societal, financial, and political efficiency of the general public can have an impact on the effect of a flood and on the ability of communities to cope with a disaster [42]. The vulnerability 
cannot be effectively defined without taking into account coping capacity, because the coping capacity of the confined population, the adjacent environment, and the resources have a foremost role to cooperate in the protection and reduction of flood effects $[1,43]$. Consequently, it is important to reach a definite outcome that integrates coping capacity for vulnerability assessment and mapping [32,44]. There are hardly any studies in the present disaster literature that use the GIS-based multi-criteria decision analysis (MCDA) technique for the adoption of coping capacities in spatial vulnerability assessments and mapping in Pakistan.

Pakistan is a country that is exposed to a range of flood hazards, earthquakes, landslides, drought, water-logging, and salinity [45]. Every year, floods have caused a huge loss of life, agricultural land, and other assets in flood-prone areas. Disaster literature indicates that Pakistan has suffered from floods almost 67 times since 1900 [5,46]. In Pakistan, the Khyber Pakhtunkhwa (KP) province is prone to different climate-related disasters due to its distinctive geography [47]. The environmental and climate-related changes further increase the susceptibility of the region to other hazards. The flood in KP mostly occurred due to heavy rainfall in the catchment of river Indus, river Kabul, and river Swat. The province faced several floods in the last few decades in early 1976, 1982, 1988, 1992, 2005, 2006, 2007, 2010, and 2014 [48]. The topography of the northern and north-eastern parts of the province is mostly mountainous, spreading from District Chitral upper to District Shangla, which is vulnerable to floods $[47,48]$. According to the District Disaster Management Plan (DDPM) Shangla, the catastrophe flood of (2010) affected 11,500 households, 200 life losses, 1000 people got injured and caused more socioeconomic damages. The District was not rehabilitated from the previous flood; another flood of 2014 and 2016 hit the region and caused 22 deaths, 281 injuries, and more infrastructural as well as economic damages [48]. Due to the frequency and intensity of flood impacts, the researchers have performed a range of studies from various perspectives of the flood phenomenon [25,47,49,50]. Most of them considered certain parameters that apply exclusively to the causes of flood hazards and their socioeconomic impacts. There have been only a few studies available in KP on vulnerability assessment [8,21,35,51]. For instance, Jamshed et al. [51] has made an effort to access the empirical connection between vulnerability and capability by using an index-based approach. Rana and Routray [21] studied three urban center populations and classified family units at various risk levels, such as risk control, survival, and coping, but their studies include theoretical conceptualization rather than statistical measurement or expert evaluation of weight allocation. Shah et al. [8] used three components of vulnerability, such as exposure, susceptibility, and adaptive capacity, to assess local inhabitants' vulnerability to flooding disasters. However, we have not come across a single study that uses a robust GIS platform approach to map out flood vulnerable areas by integrating physical, socioeconomic vulnerabilities, and coping capacity. Consequently, we have tried to access vulnerability across the target region in this study while using vulnerability mapping via GIS-based the multi-criteria decision analysis (MCDA).

\subsection{GIS-Based MCDA}

Evaluating multifaceted concerns varies over the course priorities and requirements; MCDA has a number of measures to address the complex problem across space. The spatial decision problem usually engaged a large number of conflicting criteria and alternatives evaluation. Different decision-makers evaluate this criterion and alternatives with special concerns related to the relative importance of each choice. Therefore, for these kinds of spatial problems, the researchers are focused on GIS-based MCDA, where GIS provides the tools for integrating geo-spatial data while MCDA presents an extensive collection of techniques to the issue in a simple hierarchal way [52,53]. According to Malczewski (2006), in the past several years of the 20th century, the incorporation of GIS with MCDA has drawn the attention of scientific communities. It brings a significant consideration from conventional approaches towards advanced research methodologies. The underlying inspiration from the selected literature [1,54-56] shows that MCDA in the GIS potentialities 
makes the researcher capable of take-out a timely decision and proper planning for any hazard. In the MCDA techniques, the analytical hierarchy process (AHP) is one of the most commonly utilized and accepted methods from several decades since the beginning. It has been practical to address a broad decision-making problem involving a wide range of criteria to be expressed to achieve the most optimum solution and end product through an organized estimation process from existing alternatives [55]. Currently, AHP has an inspirational significance, particularly with the incorporation of GIS and remote sensing, within the scientific community, especially in environmental science, forestry, transport, agricultural practices, water conservation and management, geology, and urban planning and management [30].

AHP has many privileges over other multi-criteria decision analysis approaches, being tolerating the obvious transactions and relationships between features and attributes. Furthermore, with the advantage of accessibility and scientific nature, AHP has been well-founded and implemented by many researchers and practitioners in a wide range of fields $[34,54,57]$. The geo-spatial approach combining remote sensing and spatial analysis is a very useful technique for drawing spatial flood vulnerability drivers, as remote sensing keeps the capacity to produce frequent satellite images for geographical environmental data, where spatial inspection help out in the compilation, investigation, and amalgamation of numerous spatial data sets $[29,58]$.

\subsection{Objectives of the Study}

District Shangla is one of the least developed District in Pakistan which is exposed to several natural hazards. Among various natural hazards, flood is the deadliest hydrometeorological hazard in the region and has brought a serious threat to the lives and property of local residents, and it has brought immeasurable influence on local economic construction and social security, which restricts the steady development of local production and life. This research seeks to devise and evaluate a multi-criteria integrated method to the assessment of flood effects employing AHP, which includes spatial analysis data combining GIS and statistical analysis, remote optical sensing, and field-level data on coping response as well as validation data. The main objective with the secondary one of the current research study is the following:

1. To access detailed flood vulnerability in District Shangla by incorporating the physical, socioeconomic vulnerabilities, and coping capacity using a GIS-based multicriteria approach.

2. To define the most influential factors affecting vulnerability in the District Shangla, a local administrative region of KP, Pakistan.

\subsection{Description of the Study Site}

This study has been carried out in District Shangla, a local administrative region of KP, Pakistan. The study area extends over $1586 \mathrm{~km}^{2}$ and ranges from $34-31^{\circ}$ to $33-08^{\circ}$ north latitude and $72-33^{\circ}$ to $73-01^{\circ}$ east latitude, as shown in (Figure 1). The District lies on the east side of Batagram and Torghar, on the west side of district SWAT, on the south side of the Buner and Torghar districts, and the Kohistan district's north side. The major river and streams of the study area are the Indus River, Khan Khwar, Lilownai Khwar, Sargar Khwar, Lal Khan Khwar, Amnavi Khwar, Chakisar Khwar, and Puran Khwar, with many adjoining torrents and Nullahs. The Indus River divides the District from the Kohistan, Batagram, and Torghar districts and flows approximately $75 \mathrm{~km}$ in the East of the study area [59]. The Khan Khwar flows from the North and joins the river Indus in the east. The Lilownai Khwar starts from the West side of the study area, which joins the river Indus at the East. At the same time, the other streams flow in different directions of the study area, as shown in Supplementary Materials (Figure S1). On one hand, these rivers and streams and are the primary sources of irrigation and electricity production in the study area. While on the other side, it generates a flood causing damages to agricultural land and more socioeconomic effects. 


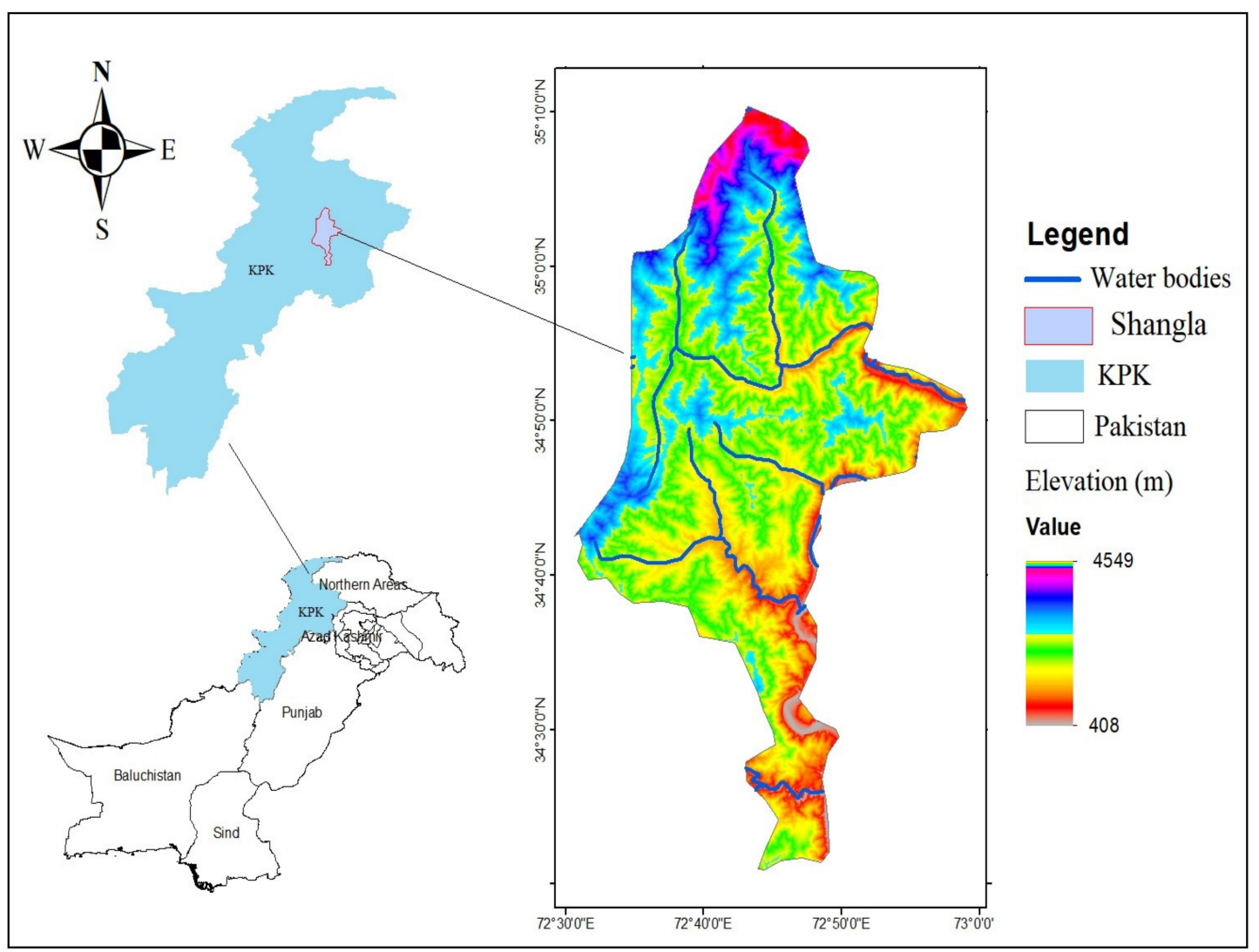

Figure 1. Study area map of District Shangla; Khyber Pakhtunkhwa, Pakistan.

According to the Pakistan Bureau of Statistics, the District's overall population is estimated to be 757,810 , with 385,741 males and 372,338 females. The aggregate number of households in the study area is 89,695 with an average family unit size of 8.1 persons per family and an average annual growth rate of $2.96 \%$.

The landscape of the District is characterized by high mountains and narrow valleys in the western extremities of the Himalayas. Climatically, the study region falls in the tropical sub-humid zone, and receives a significant amount of rainfall from the summer monsoon, while in winter the higher altitude receives snowfall [60]. The average annual rainfall ranges from $1200 \mathrm{~mm}$ to $1600 \mathrm{~mm}$ [61]. The snow melts at higher altitudes due to rise in temperature and summer rainfall in (June to September) as a result the lower catchments areas get flooded. The climatic phenomenon of the study area is shown in Supplementary Materials (Figure S2). The diagram is modified and adopted from Allen et al. [15]. The overall elevation of the District is 2000 to $3500 \mathrm{~m}$ above sea level. Farming is a major income-generating activity that depends upon rainwater and only $2 \%$ of the cultivated area depends on irrigation channels [62]. The natural forest occupied the site up to $49.9 \%$ [63]. Soil types in the study area are sandy loam to clay soil in most of the regions. The surface geology consists of Alluvium, Greenschist Melange, Jabrai Granite Gneiss, Alpuraicalcmica-garnet schist, Karora Group, Besham Group, Manglaur Formation, Darwaza Sar Potassic Granite Gneiss, and Jijal Ultramafics. The lithology of the area multifaceted and has diverse rock types [60].

The socioeconomic indicators for the particular study area are relatively low. For instance, the literacy rate is 14.5\% [64]. The District is ranked top of the other KP districts and second in Pakistan compared to scarcity, with $90 \%$ of the population living at a low standard of living due to extreme poverty [65]. In the last few years, extremely natural and anthropogenic events such as earthquakes, floods, terrorism, etc., have significantly affected the region. For instance, the earthquake struck the area on 8 October 2005, where 
444 people died, and 1925 were wounded. Consequently, the reactions of floods, disrupt the socioeconomic conditions significantly and have put them at the top of hazard priority [66].

\section{Materials and Methods}

\subsection{Method Overview}

The flood vulnerability assessment and mapping are some of the approaches that may be utilized for modelling disaster risk managing, forecasting, prevention, and mitigation [40]. In the current study, different parameters were chosen under three vulnerability components based on extensive literature $[1,7,28,29,67,68]$. Both primary and secondary data have been obtained and scrutinized for recent research. To figure out the vulnerability components attributed to flood causes and impacts; census, agriculture, education, and health data were used. Digital Elevation Model (D.E.M.) of $30 \mathrm{~m}$ resolution was used to conduct slope analysis, elevation extraction, and streams order. Similarly, precipitation data were obtained from an online open-source of National Aeronautics and Space Administration (NASA) and was analyzed for precipitation variability in the study area [58] All the variables were put together in each vulnerability component for the preparation of thematic layers. Each layer values were in different units, to convert all values into a standard scale $(0,1)$, standardization was conducted. Then all values were classified into five classes (very low to very high). All the classified values were prepared for a multi-criteria evaluation strategy based on AHP and were executed to consolidate a few common, socioeconomic, and physical criteria along with a combination of coping capacity parameters that were taken for flood vulnerability appraisal [67]. Spatial analysis in Arcmap (v10.2.2) was carried out; as a result, three individual maps (physical, socioeconomic, and coping capacity) were obtained based on the weighted linear combination method as expressed in Equation (4). Afterward, physical vulnerability indices values were multiplied with socioeconomic vulnerability in the raster calculator. As a result, vulnerability without coping capacity map was obtained. Finally, the vulnerability with an integrated map was obtained in the same way as discussed. Numbers of vulnerability calculation are present for the liability mapping of several risks. An up-to-date and utter equation can allow a constructive vulnerability judgment. In this connection, Equation (1) is chosen in this study, for flood vulnerability assessment, following the review of existing literature [1,69]. Figure 2 shows the stepwise frame of the study.

$$
\text { Vulnerability }=P V \times \frac{S E V}{C C}
$$

In the above Equation (1), (PV) represents physical vulnerability, whereas (SEV) presents a socioeconomic vulnerability and (CC) indicates coping capacity.

\subsection{Data Description and Their Sources}

Different types of data set from varied genesis were collected for constructing spatial criterion layers employing geospatial course of action, for instance, population census, agriculture, health, education, rainfall data sets, and satellite imageries. Population census data was gathered from the website of the Pakistan Bureau of Statistics (PBS), as mentioned in Table 1.

Digital Elevation Model (D.E.M.) of $30 \mathrm{~m}$ resolution was loaded from the website of the United State Geological Survey (USGS) (Table 1) to performed slope analysis and elevation extraction and other topographic factors. Precipitation data of ten years were obtained from the online source of (NASA) (Table 1) used to analyze precipitation variability in the study area. Land use and the land cover map were developed for which Sentinel-2 image of $10 \mathrm{~m}$ resolution and downloaded from USGS, Earth Explorer (Table 1). The agriculture data was obtained from the report of "Socioeconomic Indicators (2017)" KP Bureau of Statistics. Two coping capacity parameters data were acquired through field visits in the study area. Table 1 specifics description of the data and their sources for the current study. 


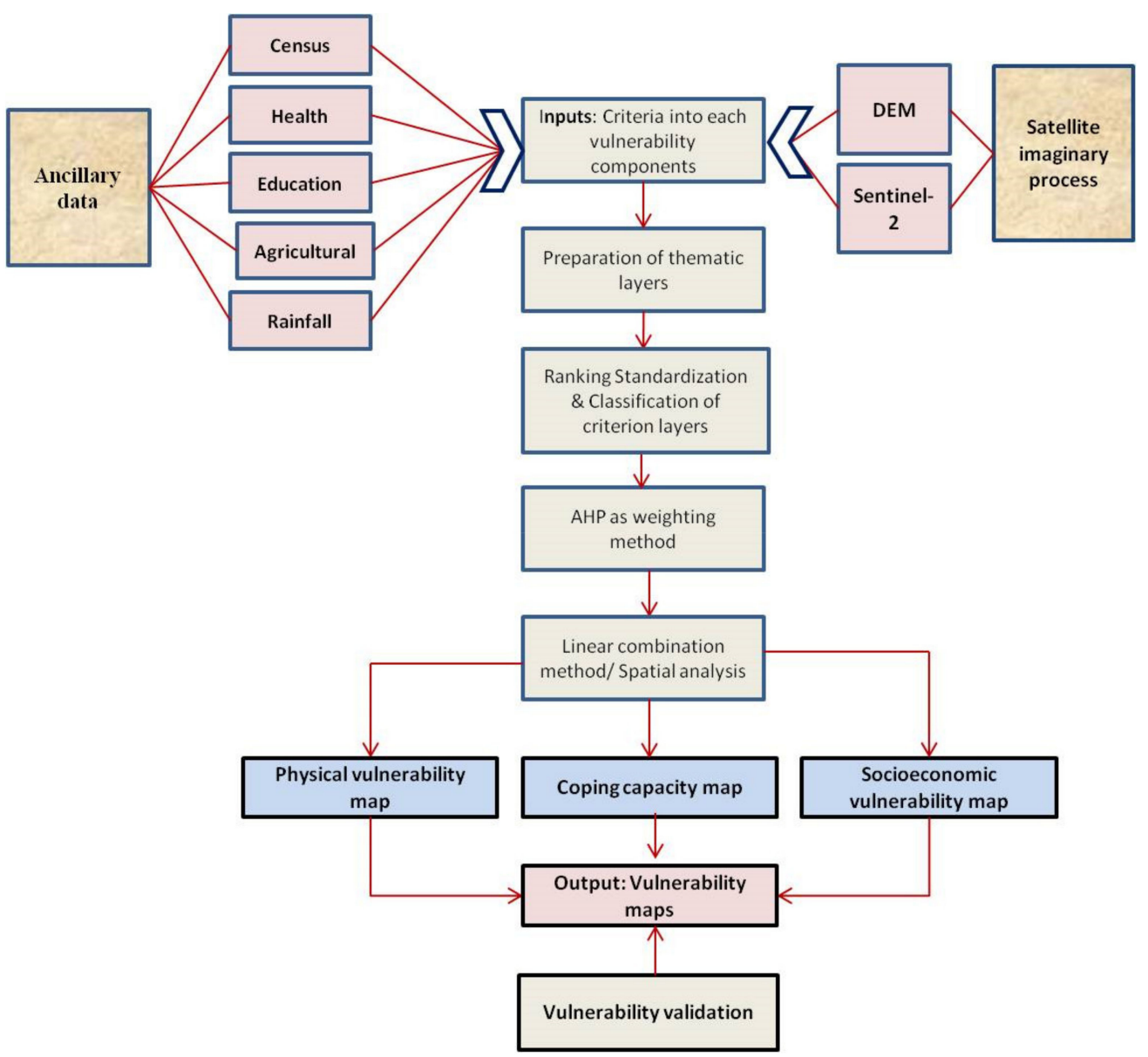

Figure 2. Stepwise framework of Methodology.

Table 1. Data type and sources used in the current study.

\begin{tabular}{|c|c|c|c|c|}
\hline S.No & Data Type & Source and Type & Period & Mapping Output \\
\hline 1 & Sentinel 2 & $\begin{array}{l}\text { https: / / earthexplorer.usgs.gov / } \\
\text { accessed on } 15 \text { October } 2019 \\
\text { USGS }(10 \mathrm{~m})\end{array}$ & 2019 & Land use and cover \\
\hline 2 & DEM (SRTM) & $\begin{array}{l}\text { https:/ / www.usgs.gov/centers/eros / } \\
\text { science/usgs-eros-archive-sentinel-2 } \\
\text { accessed on } 17 \text { October } 2019 \\
\text { USGS ( } 30 \mathrm{~m}) \\
\text { NASA }\end{array}$ & 2019 & $\begin{array}{l}\text { Slope, elevation, distance from } \\
\text { active channel }\end{array}$ \\
\hline 3 & Rainfall & $\begin{array}{l}\text { https: / / power.larc.nasa.gov / data- } \\
\text { access-viewer/ accessed on } 10 \\
\text { November } 2019 .\end{array}$ & 2019 & Precipitation Map \\
\hline 4 & Census & $\begin{array}{l}\text { Pakistan Bureau of Statistics } \\
\text { http:/ / www.pbs.gov.pk/ accessed on } \\
19 \text { August } 2020 \\
\text { (Point and statistics) }\end{array}$ & 2017 & $\begin{array}{l}\text { Population density, dependent } \\
\text { population, independent } \\
\text { population, Types of houses, } \\
\text { water sources, literacy rate }\end{array}$ \\
\hline 5 & $\begin{array}{l}\text { Agricultural and } \\
\text { forest data }\end{array}$ & $\begin{array}{l}\text { KP Bureau of Statistics } \\
\text { (www.kpbos.gov.pk) accessed on } 25 \\
\text { August } 2020 \\
\text { (Point and statistics) }\end{array}$ & 2017 & $\begin{array}{l}\text { Cultivated, uncultivated, } \\
\text { irrigated un irrigated areas }\end{array}$ \\
\hline 6 & $\begin{array}{l}\text { Health and education } \\
\text { complex }\end{array}$ & Field visits & 2020 & Education and health facilities \\
\hline
\end{tabular}




\subsection{Selection of the Criteria, Alternatives, and Their Processing}

Most of the criterion and alternatives selections were based on previous literature and, in a special context of data availability in the target locality. Those variables and alternatives were selected in the current study, which determines the flood vulnerability directly or indirectly. The geospatial layers of every nominated factor and criterion were created by mapping each decisive factor's substitutes. A total of 21 thematic maps were generated in this study under three vulnerability components. All spatial layers were transmuted into $30 \mathrm{~m}$ resolution raster ones to put in the raster-based weighted overlay process. The transformation of the value was carried out to each raster cell to prepare all criteria, respectively. The details of the criterion selection and their processing are narrated in the following modules.

\subsubsection{Criteria for Physical Vulnerability Mapping}

Natural/physical factors can incline and controlled the progression of the vulnerability of any geographical area. Physical vulnerability is related to a system's characteristics and circumstances, which make the system susceptible to any hazard [70]. In this study, physical vulnerability was examined without taking the consideration of social and cultural settings. The main focus is the natural setting of the physical environment, particularly the impacts of the flood on the built environment. These controlling factors may include land use and land cover, slope, elevation, distance to the nimble channel, rainfall potency, soil groups, drainage density, etc., but we considered only five parameters (slope, elevation, precipitation, distance to the active channel, and land use/land cover) for flood vulnerability assessment [1,29-31].

Spatial flood susceptibility evaluation is greatly influenced by elevation and slope [1]. In water-related studies, slope plays a significant role because it manages surface water flow and has power over the surface runoff. The strength of water flow gives rise to attrition of soil and vertical filtration [30,71]. The region comprising flat areas and with moderate slope is further exposed to flood compared to the area having high altitude and sharp slope [71]. The elevation is one of the key elements that control floods in a region. Plain areas may get flooded sooner as water flows from high elevated areas to low lying areas [56,72]. The height and slope criterion of geospatial layers were shown in Figure 3b,e, were created from the Shuttle Radar Topography Mission digital elevation model (SRTM DEM) $[1,28,31,73,74]$.

In Pakistan, mostly floods occurred due to irregular patterns of rainfall. Most of the literature indicates that rainfall has an unbroken connection with stream discharge. The vast volume of rainfall in a short period can cause a flash flood in the mountainous region $[47,49]$. The areas with maximum precipitation potency are more exposed to floods as compare to low precipitation intensity [67]. A map of yearly rainfall was formed by interpolating point data obtained from open access of a NASA source. Inverse Distance Weighting (IDW) interpolation technique is an extensively used procedure for interpolating metrological data like rainfall and temperature [71,75]. A precipitation map was made in ArcMap (v10.2.2) for the target locality, as shown in Figure 3d.

Land use can illustrate the socioeconomic constrain in the surface cover of the earth's definite locality. The flood's damage and special effects are immense for the defined type of land covers $[1,68,71]$. The study area was classified into build-up, agricultural, forest, water bodies, snow cover, and rangeland classes from Sentinel-2, as shown in Figure 3a. The classification method known as supervised classification is one of the most use by the different researchers in their studies. To find out the probable classes and then, training sample data were chosen and utilized to perform a maximum likelihood algorithm in ERDAS IMAGINE [76]. 300 random points were taken from high-resolution Google Earth imageries to perform an accuracy assessment (2019) of the study area. To obtain the reference points with at least 60 points for respectively cover class, a stratified random sampling method was used. Tailed the methods described to achieve an accurate 
assessment of classified imagery. The accuracy assessment result shows that the image is classified with $90 \%$ [74,76-78].

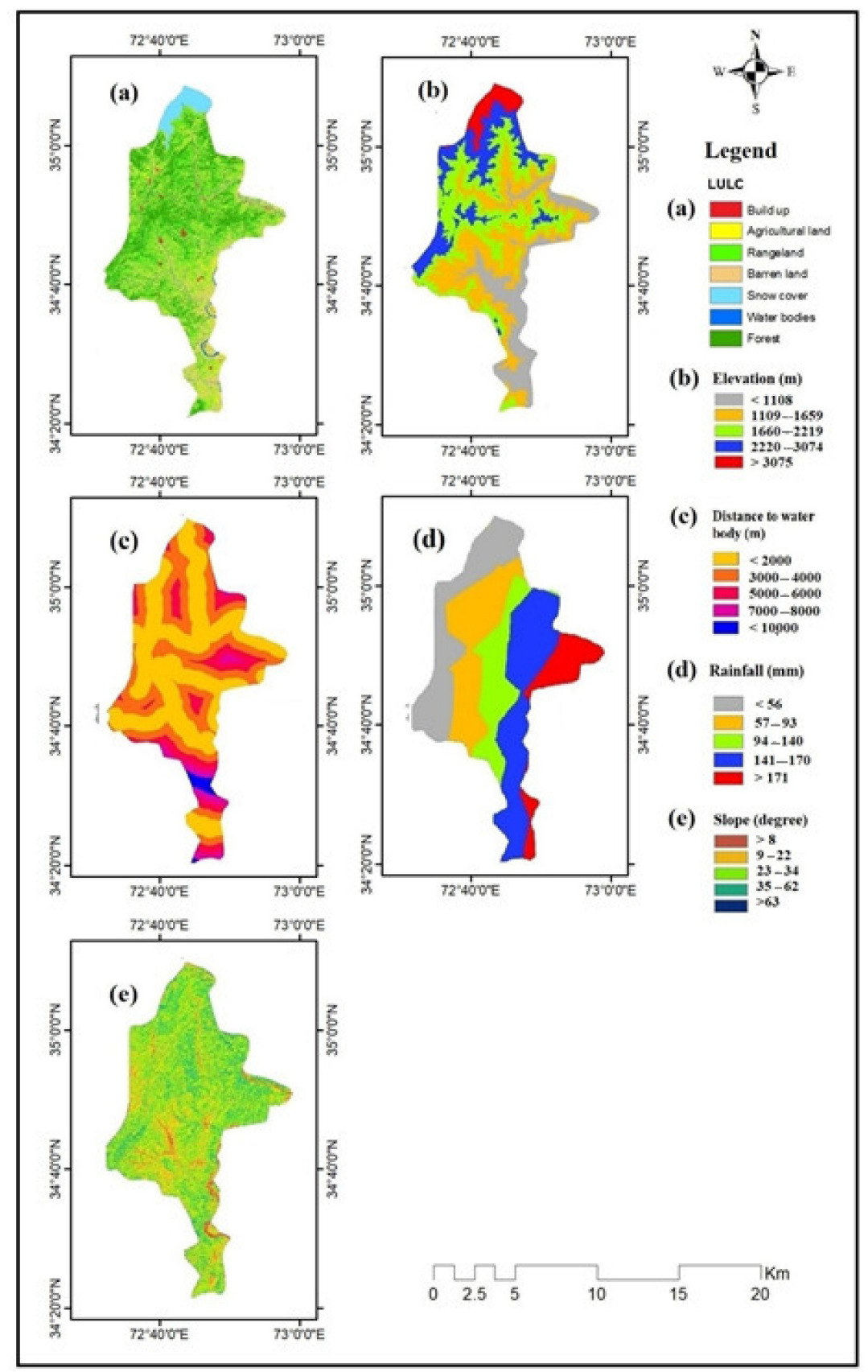

Figure 3. Physical vulnerability criterion layers: (a) land use and cover, (b) elevation, (c) slope, (d) distance to active channel, (e) precipitation.

Distance to the active channel is one of the most important aspects of flood vulnerable areas. Most of the area is defenseless nearby to the active channel to floods as compared to the area, away from the channel $[1,16]$. To assess, river channel data were obtained for creating distance to active channel maps in the study area shown in Figure 3c [74].

\subsubsection{Criteria for Coping Capacity Mapping}

The reflection of coping capacity in the system ameliorates adaptation responses and steers to preferable mitigating disaster consequences. Following the United Nations 
International Strategy for Disaster Reduction [42] (p. 9), Coping capacity imply to the blend of all the resources, potency, and impute accessible within a locality, society, or association to deal with the unpleasant situation, emergencies or calamity by using existing skills and resources to face and cope with negative impacts. According to UNDRR 2019, coping capacity is the ability of a system, individual, or community to respond to the negative impacts of stress or perturbation that have the potentials to change the structure or function of the system [40]. Different studies take different parameters for the evaluation of coping capacity. For instance, Roy et al. [24] used three coping capacity domain as (1) assets (household with radio, television, bicycle, mobile, and agriculture land); (2) education (literacy rate, and school attendance rate); and (3) economic alternatives, (proportion of non-agriculture worker and distance to town). While Houqe et al. [1] used three parameters (literacy rate, distance to flood shelter, and distance to health complexes) for calculating the coping capacity of Kalpara Upazila in Bangladesh. Three coping capacity criteria, which are distance to Education facilities, distance to health complex, and literacy rate were considered in the current investigation.

The existence of education and health facilities within the community are essential criteria for determining the coping capacity of a specific locality because, in case of emergency, the residents of the community can use the education building as a shelter and their closeness to health facilities can reduce the mortal losses due to adequate treatment within time so, these factors help in alleviating disaster effects $[43,68,79]$. In this study, education and health complex data were gained from the concerned departments of statistics. Spatial layers were formed employing the "Euclidean distance" method in the ArcMap platform $[54,80]$, as shown in Figure 4b,c.

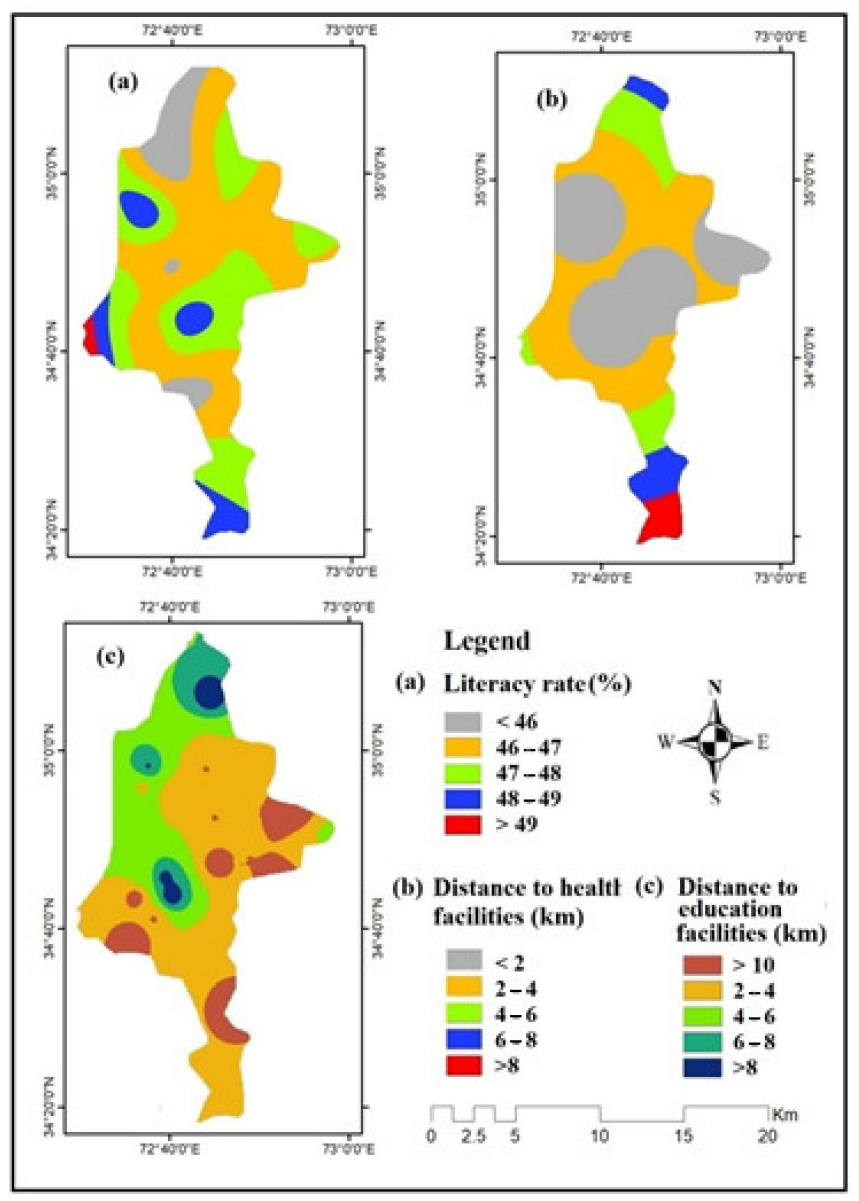

Figure 4. Coping capacity criterion layers: (a) literacy rate (b) distance to health facilities (c) distance to education facilities. 
Literature has revealed that literacy can develop knowledge, awareness, and flexibility against flood tragedy and help folks make the proper decision and engage in helpful mitigation processes recuperating from disaster outcomes [1,35]. Researches demonstrate that a family unit with educated individuals exhibits maximum coping ability with disaster effects compared to the household with uneducated people [35,81]. The literacy rate data of 10 years and above schooling were taken out from the 2017 population census, and the spatial stratum was shaped in the ArcMap, as shown in Figure 4a.

\subsubsection{Criteria for Socioeconomic Vulnerability Mapping}

Various social and economic criteria influence socioeconomic vulnerability to floods. Socioeconomic vulnerability is a utility of the community's features that made them susceptible to flood impacts and possible natural resource changes $[18,82]$. There is also a necessity to examine and establish the proper selection of indicators for assessments using the frame to determine socioeconomic vulnerability [83]. Several studies have shown that preferences should be based on the related literature's cooperation facts and a comprehensive perceptive of the local background that provides adequate local relevance to adapt local adaptation measures [19,32]. Multiple criteria can persuade the socioeconomic vulnerability to floods. Such criteria were chosen here for mapping. Overall, in this study, 11 criteria are sorted out, including population density, dependent population, independent population, water facilities, uncultivated and cultivated land, irrigated and un-irrigated land, Kacha houses (those dwelling units which is made-up of un-brunt bricks, mud, and loosely packed stones), and Pacca houses (those dwelling units which are designed to be solid and permanent and were made-up of bricks, steel, concrete, and are more resistant to flood).

Population density is one of the principal criteria for assessing social vulnerability, particularly that people in the specific locality are physically and mentally exaggerated by flood from different angles [1]. The overpopulated groups especially find it hard in expulsion activities during and after the flood event [79]. A population density thematic map was created using the population census data of 2017, as shown in Figure 5c. The locality with densely inhabited is likely to be more exposed to floods than the area with low population density. Water source and cleanness of place are a significant basis for evaluating social vulnerability to floods, because floodwater causes damaged to the water supply scheme, which leads to meagre hygienic sanitation systems, and health-associated problems. In such circumstances, inadequate access to safe water and water-borne disease greatly suffer a large number of people [6,84]. The freshwater sources were split into five categories and mapped as shown in Figure 6e.

The female population is weaker than the male population [85]. For example, relative populations, like children and aged people, are very susceptible to flood because of their slight movement and troubles in emergency emptying activities [1]. For the current study, the needy and self-governing population's spatial thematic layer was created using the 2017 population census data as shown in Figure 5a.

Flood exposure is mostly affected by the housing quality in a given area. Such a kind of house is a significant aspect of flood threat $[8,35]$. Houses are grouped into two categories, Kacha (which is made up of stone and mud) and Pacca houses (which are made up of bricks, steel, and concrete). Pacca houses are more resilient to flood as compared to Kacha houses. The population census of 2017 was used to prepare the spatial layers of house type in this study Figure 5d,e. 


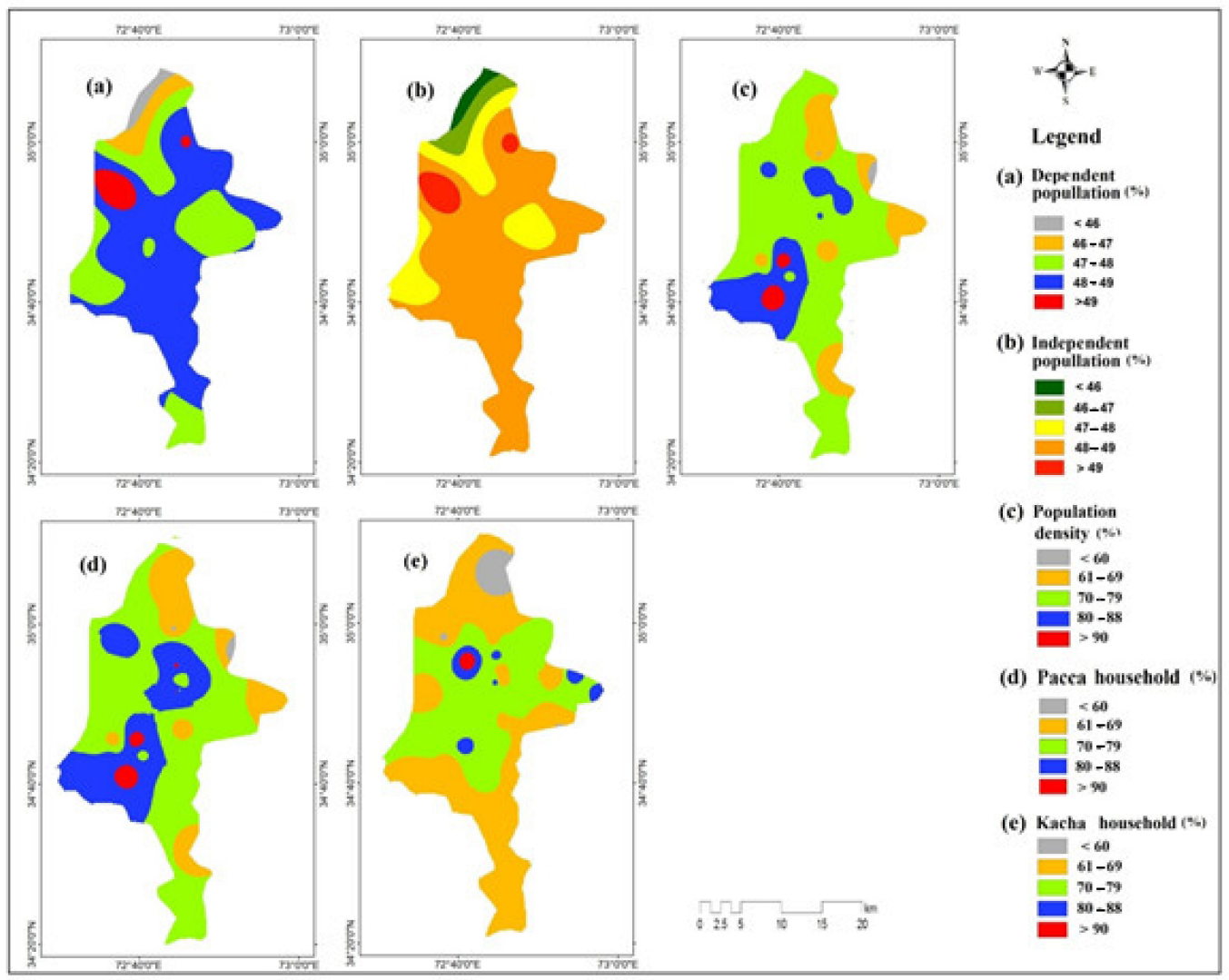

Figure 5. Socioeconomic vulnerability criterion layers: (a) dependent population, (b) independent population, (c) population density, (d) Pacca household, (e) Kacha household.

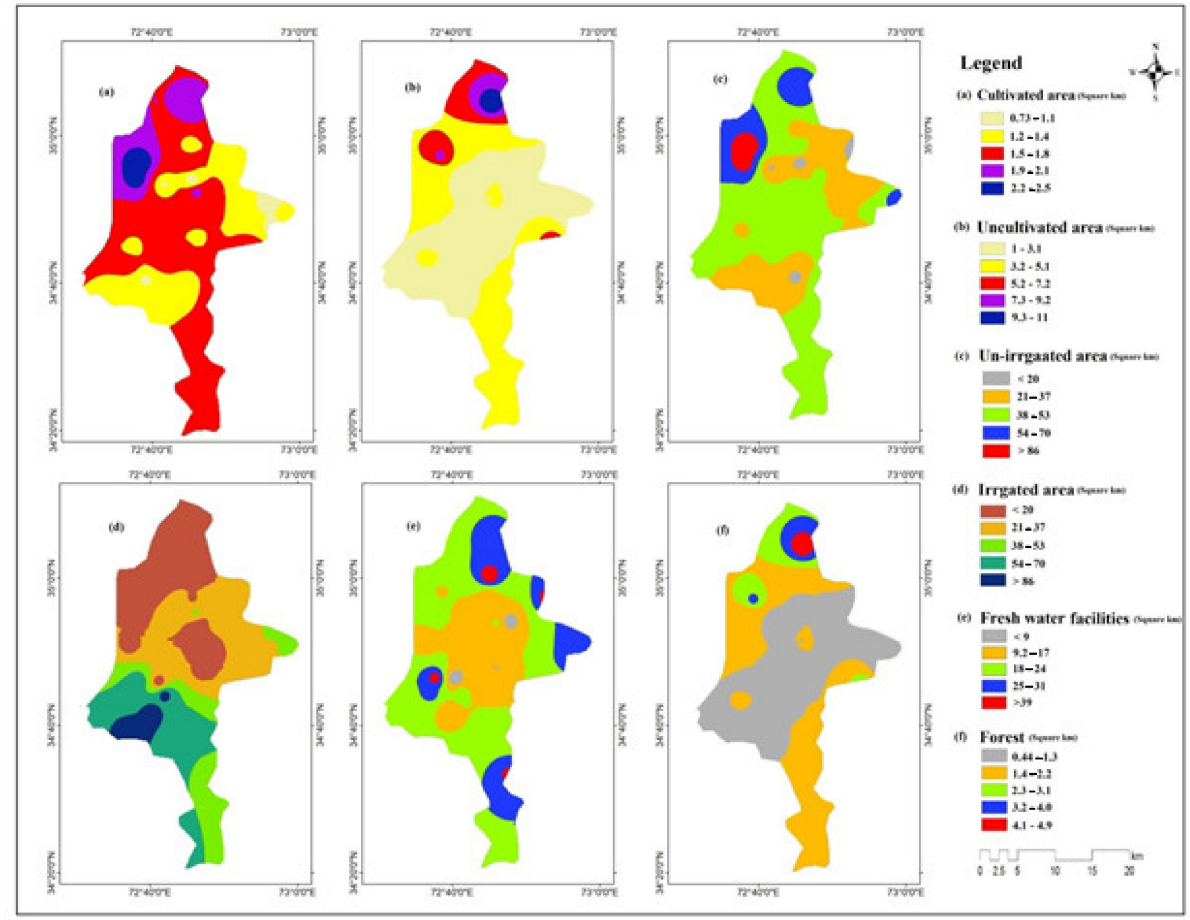

Figure 6. Socioeconomic vulnerability criterion layers: (a) cultivated area, (b) uncultivated area, (c) un-irrigated area, (d) irrigated area, (e) freshwater facilities, (f) forest. 
Floods cause wide devastation to crops and caused more damages in terms of economic losses [47,55]. In this study, the agriculture-dependent spatial layer was drawn up by classifying into cultivated, uncultivated, irrigated, and un-irrigated spatial layer by inverse distance weighting interpolation (IDW) methods in the GIS environment using point data gained from the KP bureau of statistics (Kp.bos) and district agriculture department. Cultivatable and irrigated extents performances an essential role in the state economy [51]. In the 2010 flood, the water spilled and scattered a substantial capacity where it distributed on, containing cultivated land, irrigation channels, river beds, infrastructures, and houses [5]. Mainly, the un-irrigated area is usually not affected by the flood as compared to the irrigated area, but the un-irrigated area speeds up the flow of water because of a lack of proper ways for water flowing. Spatial layers were generated and classified into five zones according to the percentage of area that is cultivated, uncultivated, irrigated, and un-irrigated as shown in Figure 6a-d).

\subsubsection{Alternative Ranking, Standardization, and Classification of Criterion Layer}

The most important use of AHP is to rank and prioritize the constraint. The preference scheme and the efficiency of existing sources which are the prerequisite judgement from the decision-maker. Moreover, the professionals generally exercise the pragmatic understanding when they are concluding the decision in the available alternatives, criteria, and sub-criteria. The ranking was carried out on the mapped surrogate each of the spatial criterion strata, hereby providing the degree of vulnerability ( 1 to 5 ). From Ranks 1 to 5 shows very low to very high vulnerabilities, correspondingly [29]. Ranking of alternatives was carried out following the researcher's contribution to vulnerability and AHP exercise (Table 2).

For standardization and classification, relatively two strategies were assumed to convert all criteria into a common scale. Standardization of values on the scale of $0-1$. While classification was applied to make five stable values were endorsed to five clusters of the factor values. For the current study, the natural break was used to classify each criterion value in simple classification methods in the ArcMap (v10.2.2) software. All spatial layers were altered into $30 \mathrm{~m}$ pixel raster ones to apply the raster-based weighted overlay procedure, the values transformation was performed in each raster cell to prepare all criteria for the weighting linear combination that results [24]. The values transformation was executed on each raster cell to design all criteria for the weighting linear combination. Thus, the values of reclassification were assigned to the range between 0 (not vulnerable to flood) and 1 (flood susceptible) for the first approach of standardization. Proportionally, giving rank to the alternative of the values $1,2,3,4$, and 5 (for very low, low, moderate, high, and very high susceptibility) are attributed when performing the classification approach to provide vulnerability levels. Thus, the criterion standardization procedure is made through the Raster Calculator while the classification into five classes was performed via ERDAS 6.3.0 using the K-means algorithm, and then their reclassification in 1-5 was performed in Arc Map [86,87].

\subsubsection{Weighting the Criteria Using AHP}

AHP is a tool of multi-criteria approach for assessing disaster vulnerabilities, site selection, allocation of resources, etc., which transforms the subjective evaluation into quantitative information with the help of assigning scores of various criteria and sub-criteria. This approach leads the qualitative methodology which relies on specialist views. The proposed research has taken the judgment of experts from the field of hydrology and disaster management. The experts have been selected based on basic knowledge and research experience. While doing the weight allocating process the whole procedure is divided into five steps: pairwise comparison of criteria with expert opinion, aggregation of the expert opinion, forming the preference matrix as shown in Supplementary Materials (Tables S1-S3), finding a normalized matrix as shown in Supplementary Materials (Tables S4-S6), and the calculation of the consistency ratio. All the steps are discussed below. 
Table 2. Alternate grading arrangement based on the input to a flood disaster.

\begin{tabular}{|c|c|c|c|c|c|c|}
\hline \multirow{2}{*}{ Component } & \multirow{2}{*}{ Criteria } & \multicolumn{5}{|c|}{ Vulnerability Ranking } \\
\hline & & Very High (5) & High (4) & Moderate (3) & Low (2) & Very Low \\
\hline \multirow{5}{*}{ Physical vulnerability } & Slope (degree) & $<8$ & $9-22$ & $23-34$ & $35-62$ & $>63$ \\
\hline & Elevation (meter) & $<1108$ & $1109-1659$ & $1660-2219$ & $2220-3074$ & $>3075$ \\
\hline & Distance from active channel (meter) & $<2000$ & $2000-3000$ & $5000-6000$ & $6000-7000$ & $>10,000$ \\
\hline & LULC & Settlement & Cropland-Grassland & Bare land & Forest & Snow cover-water bodies \\
\hline & Precipitation (mm) & $>171$ & $141-170$ & 94-140 & $57-93$ & $<56$ \\
\hline \multirow{9}{*}{ Socioeconomic vulnerability } & Population density $\left(\mathrm{km}^{2}\right)$ & $>1100$ & $860-1100$ & $640-860$ & $410-630$ & $<400$ \\
\hline & Independent population (\%) & $>53$ & $51-52$ & $49-50$ & $47-48$ & $<46$ \\
\hline & Cultivated area $\left(\mathrm{km}^{2}\right)$ & $>2.2$ & $1.9-2.1$ & $1.5-1.8$ & $1.3-1.4$ & $<1.1$ \\
\hline & Uncultivated area $\left(\mathrm{km}^{2}\right)$ & $<3.1$ & $3.2-5.1$ & $5.2-7.2$ & $7.3-9.2$ & $>9.3$ \\
\hline & Irrigated area $\left(\mathrm{km}^{2}\right)$ & $>86$ & $54-70$ & $38-53$ & $21-37$ & $<20$ \\
\hline & Un irrigated area $\left(\mathrm{km}^{2}\right)$ & $<20$ & $21-37$ & $38-53$ & $54-70$ & $>86$ \\
\hline & Kacha houses $(\%)$ & $>89$ & $80-88$ & $70-79$ & $61-69$ & $<60$ \\
\hline & Pacca houses (\%) & $>90$ & $80-88$ & $70-79$ & $61-69$ & $<60$ \\
\hline & Fresh Water facilities (\%) & $>39$ & $25-31$ & $18-24$ & 9-17 & $<9$ \\
\hline Coping capacity & Distance form health complex (km) & $>8$ & $6-8$ & $4-6$ & $2-4$ & $<2$ \\
\hline
\end{tabular}


Initially, we prepared three comparison matrixes for physical, socioeconomic vulnerabilities, and coping capacity. The qualitative judgment from the experts' opinions was received based on the Saaty nine-point scale of relative importance [88] (Table 3). According to Saaty fundamental scale (Table 3), the pairwise comparison is practiced to find out each criterion weight [30]. In this regard, we considered some facts from the literature $[1,29,67,68,84]$ and interrogate the experts independently to discuss the significance of one criterion over another. Four experts were interrogated using the independent judgment method [89]. A questionnaire to each expert was handed over, and the geometric mean was taken to give each criterion the final values as shown in Supplementary Materials (Tables S1-S3). Ultimately, the preference matrix is generated according to Table 3 with the literature and expert opinion. The scale values are used from equal importance to extreme importance having a numerical value from 1 to 9 . The fundamental of the pairwise correlation matrix was to deliver the best option to the weight set. Weight value means the significances, which are absolute numbers somewhere in the range of zero and one. Utilizing a weighted straight combine, it derives that the entirety of the weight to the total sum of one [1,29]; therefore, the total score for three components of vulnerability was kept as one. An inventory of the flood contributing elements or factors development indicating the few factors, their particular weight, and how they are reviewed by their impact on flooding causes in the study area. Greater weight estimation of the criteria shows more need or impact than others inside the study [54,67].

Table 3. Showing the intensity and scale of importance [88].

\begin{tabular}{cll}
\hline Intensity of Importance & Definition & \multicolumn{1}{c}{ Explanation } \\
\hline 1 & Equal importance & $\begin{array}{l}\text { Two elements provide a similar } \\
\text { influence to the objective }\end{array}$ \\
\hline 5 & Strong importance & $\begin{array}{l}\text { Knowledge and decision strongly } \\
\text { favor one factor over another } \\
\text { favor one factor over another }\end{array}$ \\
\hline 7 & Very strong importance & $\begin{array}{l}\text { One factor is preferred very } \\
\text { strongly and is measured greater } \\
\text { than another; its dominance is } \\
\text { demonstrated in practice }\end{array}$ \\
\hline 9 & Extreme importance & $\begin{array}{l}\text { Capability and finding toughly help } \\
\text { one factor over another }\end{array}$ \\
\hline $2,6,8$ & The same importance & When compromised is needed \\
\hline
\end{tabular}

Measuring the Consistency

By doing so the AHP process, the expert's and users' assessment are based on individual judgment so, they are not excepted from personal preferences and subjectivity, raising the likelihood of generating unreliability in concluding them $[55,89]$. For that type of indecision, the researcher performs the consistency check to evaluate whether the comparative judgment is reasonably consistent or to repeat the practice before further processing [88].

In this study, the consistency ratio $(C R)$ was figured out for checking the dependability of comparisons in the pairwise correlation grid. $C R$ is measured if the value is equivalent to or small to affable level $(10 \%)$ than the consistency ratio $(C R)$ and the consistency index $(C I)$ [90]. The $C R$ is defined as the ratio between $C I$ and $R I$. Consistency ratio is given by Equation (2), where $R I$ is the standard value as shown in Supplementary Materials (Table S7) according to the number of criteria used in various research performance [88].

Equation (2) shows consistency ratio; where " $C I$ " is the consistency index and " $R I^{\text {" is }}$ the random index.

$$
C R=\frac{C I}{R I}
$$


$C I$ is expressed as

$$
C I=\frac{(\lambda \max -n)}{(n-1)}
$$

where $\lambda \max$ (Tables S8-S10) in the Supplementary Materials implies, the product between column-wise sum in pairwise comparison matrix and the average weight from the normalized matrix and prime value of the matrix and the matrix's order is indicated by $n$.

The resulting CR value is $0.05,0.09$, and 0.02 , respectively, as shown in (Table 3 ) which is satisfactory because the toleration limit for the observed incontinency is at 0.1 [89].

\subsubsection{Linear Weighted Combination Method}

The most significant and common method employed in flood vulnerability mapping is the weighted linear combination method. It uses a linear superposition approach based on the importance of different factors' weight. Linear combination converts multi-factor evaluation into a comprehensive one [91]. The following Equation (4) was used for the weighted linear combination.

$$
\mathrm{VI}=\sum_{i=1}^{n} f_{i} \times x_{i}
$$

where VI is the vulnerability index, $n$ is the total number of factors, $f i$ represents the weight of factors $i$, while $x i$ describes the contribution index of different factors $i$. To follow the WLC approach for producing flood vulnerability mapping of three steps that can be performed comprises data processing, weighting, and mapping [92]. Different criteria were re-classified while using ranking and then finally using a weight liner combination model to produce physical, socioeconomic vulnerability, and coping capacity maps of the study area.

\subsection{Vulnerability Evaluation}

In vulnerability study, several criteria are of much importance than others, for the purpose being numerical weighting score is allocated to every criterion layers according to its relative significance by using the layer principle. For the vulnerability evaluation in the present study, the authors independently practiced the weighted overlay technique with three components decisive factor layers by including their associated criterion weights. Thus, the indexes of three components of physical, socioeconomic vulnerabilities, and coping capacity were got. After this, to create the maps of these three components, the exact index value was divided into five classes, i.e., very low, low, moderate, high, and very high. Then, multiply the physical vulnerability indices to socioeconomic vulnerability indices without integrating the coping capacity. Later on, to achieve the Equation (1) values, the vulnerability included coping capacity index was produced by accumulating physical vulnerability with socioeconomic vulnerability and then dividing by the coping capacity in the ArcMap (v.10.2.2) to obtain the final vulnerability product.

Consequently, the weighted linear combination model was used to produce the physical, socioeconomic vulnerabilities, coping capacity map, and an integrated map of the study area. The natural break statistical scheme was adopted to categorize the flood vulnerability map. The particular method is more reliable and competent to give out the spatial pattern of flood vulnerability in the location-specifically [1,71].

\section{Results and Discussion}

\subsection{Physical Vulnerability Mapping}

In this study, physical vulnerability was examined without taking the consideration of social and cultural settings. The main focus is the natural setting of the physical environment, particularly the impacts of the flood on the built environment. In this study, we take five criteria, which are land use/landcover, elevation, slope, distance from the active channel, and precipitation as discussed in (Section 2.3.1) while following the literature of $[1,29]$. On the other hand, Feloni et al. [87] used nine parameters, while Matej et.al [30] used seven parameters for flood susceptibility mapping of Slovakia. While Kashif et al. [71] 
used seven parameters to determine the flood susceptibility at Panjkora river basin. As a result, it should be stated that no exact agreement exists on which parameters should be applied for physical vulnerability analysis. However, Matej et al. [30] recommend six parameters in order to not generate unrepresentative weights dominated by a single weight which may raise the possibility of over-rating some of flood contributing parameters. The number of parameters should be adjusted with respect to local built environment conditions since the urban area may require other parameters than rural areas [30]. In this study, all the selected indicators were divided into sub-indicator and ranked as 1 to 5 , where 1 represents very low vulnerability and 5 represents a very high vulnerability to flooding. The detailed statistics and ranking are shown in (Table 2). Weighted linear combination method (Equation (4)) in ArcMap (v10.2.2) spatial analysis was followed to integrate all the AHP weights of physical vulnerability (Table 4 ) to create a $30 \mathrm{~m}$ pixel by pixel physical vulnerability database. The output database's physical vulnerability index values range from 0 to 1 , where zero refers to very low vulnerability and one refers to very high vulnerability. The data was reclassified to five categories through manual classification method [56] such as; (1) very low $(0.05-0.08)$, low $(0.08-0.12)$, moderate $(0.12-0.30)$, high $(0.30-0.60)$, very high $(0.60-1)$ vulnerability respectively. Very low vulnerability reflects that the area with a high elevation and faraway from active channel then has no chances of flood occurrence. However, the impacts will not be ignored because most of the population live in high elevated mountains and entirely dependent on the plain areas using as a source of their daily life activities. While very high vulnerability category shows more chances of flood occurrence as well as a high impact in a specific area. After that, a spatial analysis operation was done; as a result, different vulnerability level maps were obtained. The particular map (Figure 7) shows that roughly $59 \%$ of the research was stratified into a very low to moderate vulnerability level which covers an area of $1106 \mathrm{~km}^{2}$, while high and very high vulnerable areas secured $41 \%\left(490 \mathrm{~km}^{2}\right)$ of the total area (Table 5). The central-southern and eastern areas are severely susceptible to flood impacts since they are close to the waterways Figure $3 \mathrm{c}$ displays low-water marks and delicate slants Figure $3 \mathrm{e}$. By comparison, due to lofty altitude Figure $3 \mathrm{~b}$, in a vertiginous slope, and faraway from the active river channel, northern and north-western regions from the central parts are at a less vulnerable level. The results indicate that the area closeness to the bank of the river and gentle slope are important parameters of physical-environmental vulnerability. The finding of this study reveals that the area closeness to active channel is highly exposed to flood impacts. The results agree with the previous studies $[1,8,24,45,51]$, which shows that areas near to river, streams, situated on a slight slope and receive maximum rainfall will be highly vulnerable to flood impacts.

Table 4. Weighting the criteria using analytical hierarchy process (AHP).

\begin{tabular}{|c|c|c|c|}
\hline Components of Vulnerability & Criteria & Weight & Priority \% \\
\hline & Elevation & 0.29 & $29 \%$ \\
\hline & Slope & 0.07 & $7 \%$ \\
\hline & LULC & 0.08 & $8 \%$ \\
\hline \multirow[t]{7}{*}{ Physical vulnerability } & Precipitation & 0.19 & $19 \%$ \\
\hline & Distance from the active channel & 0.41 & $41 \%$ \\
\hline & $\mathrm{CR}$ & 0.05 & \\
\hline & Un-cultivated area & 0.049 & $4.90 \%$ \\
\hline & cultivated area & 0.051 & $5.10 \%$ \\
\hline & Forest & 0.031 & $3.20 \%$ \\
\hline & population density & 0.18 & $18 \%$ \\
\hline
\end{tabular}


Table 4. Cont.

\begin{tabular}{|c|c|c|c|}
\hline Components of Vulnerability & Criteria & Weight & Priority $\%$ \\
\hline \multirow[t]{9}{*}{ Socioeconomic vulnerability } & Dependent population & 0.128 & $12.80 \%$ \\
\hline & Independent population & 0.142 & $14.20 \%$ \\
\hline & Irrigated area & 0.081 & $8.10 \%$ \\
\hline & Un-irrigated area & 0.056 & $5.60 \%$ \\
\hline & Kacha houses & 0.95 & $9.50 \%$ \\
\hline & Water facilities & 0.045 & $4.50 \%$ \\
\hline & Pacca houses & 0.12 & $12 \%$ \\
\hline & CR & 0.09 & \\
\hline & Literacy rate & 0.07 & $7.30 \%$ \\
\hline \multirow[t]{3}{*}{ Coping capacity } & Distance from education facilities & 0.58 & $58 \%$ \\
\hline & Distance from health complex & 0.34 & $34.95 \%$ \\
\hline & $\mathrm{CR}$ & 0.02 & \\
\hline
\end{tabular}

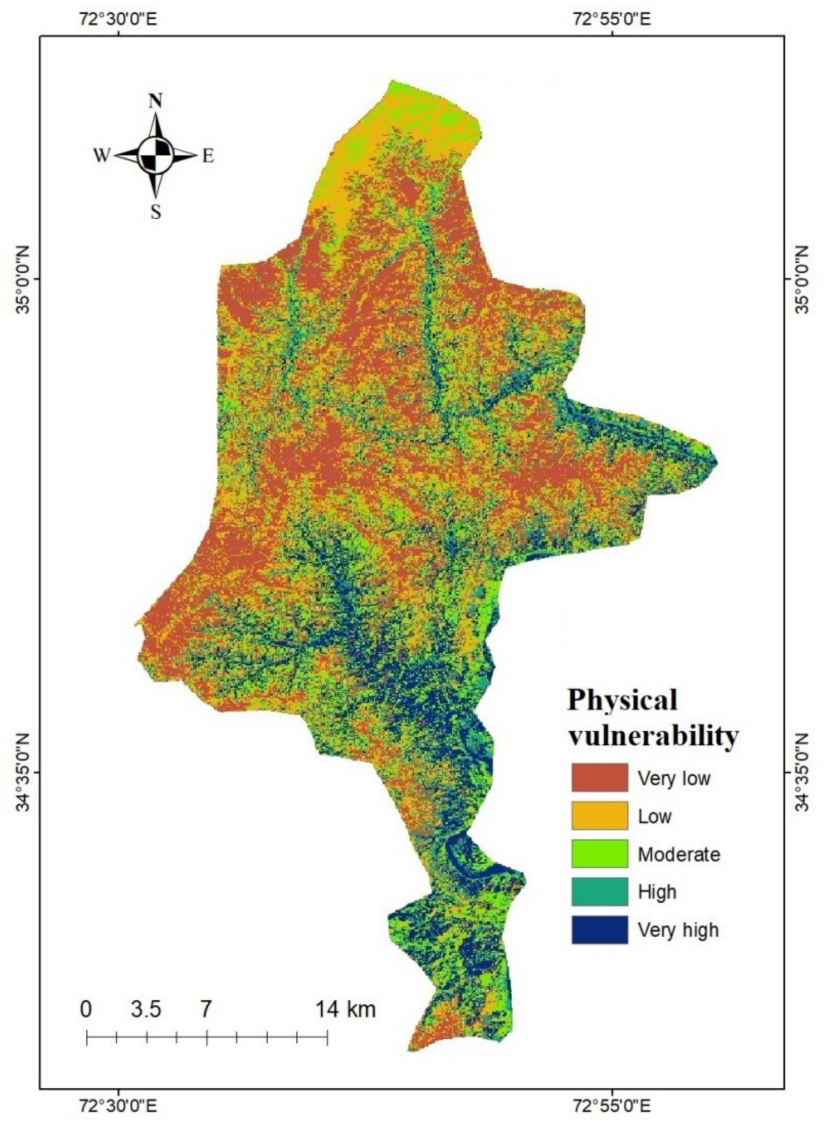

Figure 7. Physical vulnerability map displaying spatial pattern and levels of physical vulnerability to floods.

Table 5. The physical vulnerability of the study area after reclassification.

\begin{tabular}{cccc}
\hline Vulnerability Level & Area in sq.km & Area $\%$ & Direction \\
\hline Very low & 207.76 & 13.02 & Northern \\
Low & 440.07 & 27.60 & Northern-western \\
Moderate & 457.63 & 28.71 & Central \\
High & 326.11 & 20.46 & Central-southern \\
Very high & $\mathbf{1 6 2 . 9 5}$ & $\mathbf{1 0 . 2 2}$ & Southern-eastern \\
\hline
\end{tabular}




\subsection{Coping Capacity Mapping}

Coping capacity is the ability of a system, individual, or community to respond to the negative impacts of stress or perturbation that have the potentials to change the structure or function of the system [40]. Coping capacity refers to the blend of all resources, skills, and knowledge within a locality to deal with an unpleasant situation using existing sources and abilities to cope with adverse impacts. Different studies take different parameters for the evaluation of coping capacity. For instance, Roy et al. [24] used three coping capacity domain as (1) assets (household with radio, television, bicycle, mobile, and agriculture land); (2) education (literacy rate, school attendance rate); and (3) economic alternatives, (proportion of non-agriculture worker and distance to town). While Houqe et al. [1] used three parameters (literacy rate, distance to flood shelter, and distance to health complexes) for calculating the coping capacity of Kalpara Upazila in Bangladesh. In this study, we used three criteria: distance to education buildings, distance to health complexes, and literacy rate. All the selected criteria were divided into sub-criteria and ranked from 1 to 5 and further process same as discussed before (Section 2.3.2). The coping capacity map was produced by classifying them into five levels based on developed index values. Table 6 presents that high to highly resilience levels spread up to $20 \%$ of the research area mostly spread from southern to the northern direction, which mostly covers an area of $305.41 \mathrm{~km}^{2}$. The coping capacity of the central area is higher as compared to the northern and southern parts of the study area because of the numerous flood shelters, and health complexes. By contrarily, from low to very low coping capacity tract cover $46 \%\left(725 \mathrm{~km}^{2}\right)$ of the targeted study area comparing to the central area of the study. The inhabitants' in the particular areas have good access to health and educated buildings, and better approaches to freshwater facilities. The education and health complexes act like shelter to flood during flood disaster phenomena. Educated and aware society can successfully adapt towards flood vulnerability because these individuals know the measures, which they need to take during flooding after flood. While the remaining area of $563.69 \mathrm{~km}^{2}$ falls into moderate vulnerable hazard level as shown in Figure 8. The finding of this study discloses that those areas which have more education facilities and have easy access to these facilities will be more resilient. In emergencies, the affected people always try to find shelter to save their lives and assets. Therefore, the education buildings are one of the primary sources that one can use as shelter. Our results confirms similar findings carried out by Shah et al. [8] and Hoque et al. [1]. Which implies that community immediate access to a safe place will reduce the disaster effects and the number of education facilities will increase the capacity of a community. The community closeness to health facilities could reduce the mortal losses due to an inadequate treatment within time. This indicating that the closeness of community to health facilities can reduce the disaster effects and increases their resilience toward flood hazards.

Table 6. Coping capacity of the study area after reclassification.

\begin{tabular}{cccc}
\hline Coping Capacity & Area in $\mathbf{k m}^{\mathbf{2}}$ & Area $\%$ & Direction \\
\hline Very low & 12.01 & 0.76 & Central \\
Low & 713.40 & 44.75 & Central-western-eastern \\
Moderate & 563.69 & 35.36 & Central-western \\
High & 301.07 & 18.89 & Southern-northern \\
Very high & $\mathbf{4 . 3 4}$ & $\mathbf{0 . 2 8}$ & Southern \\
\hline
\end{tabular}




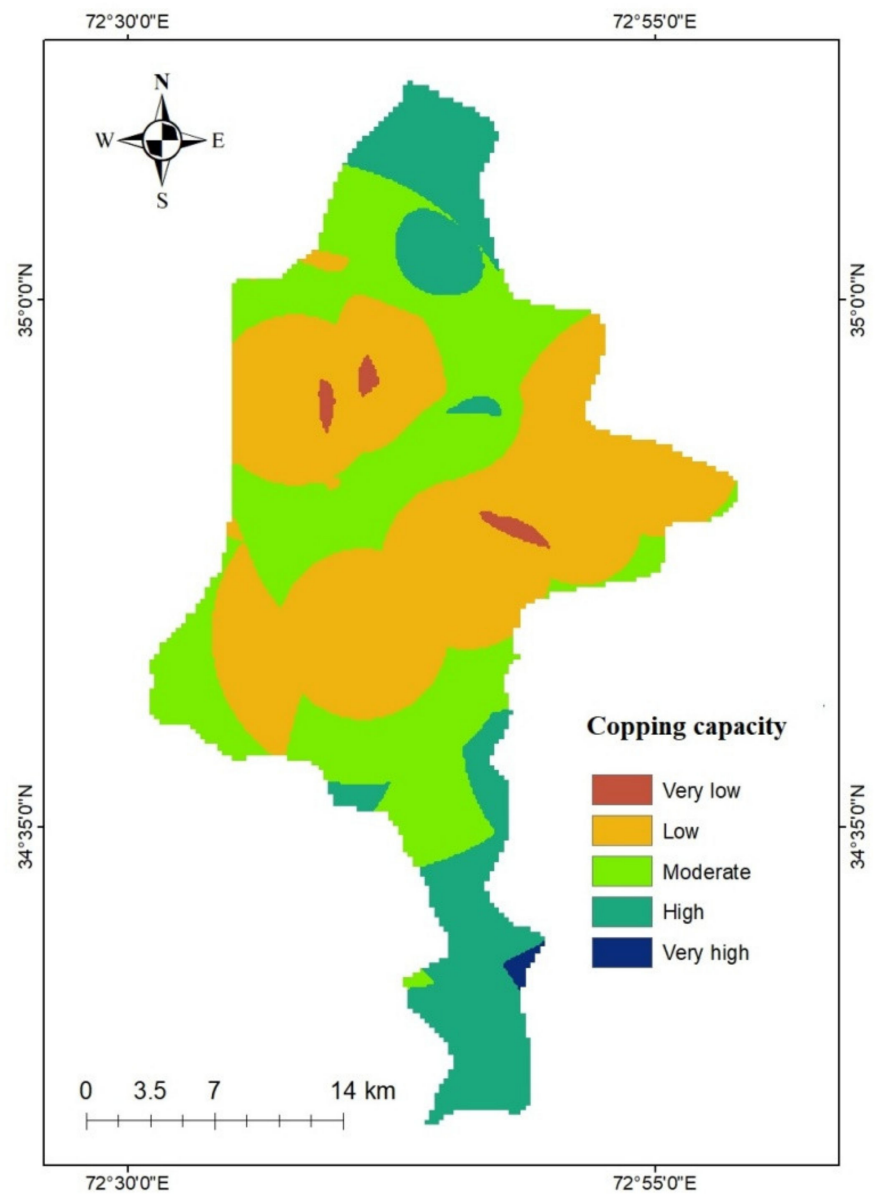

Figure 8. Coping capacity map displaying spatial pattern and level of coping capacity against floods.

\subsection{Socioeconomic Vulnerability Mapping}

Socioeconomic vulnerability is the social, economic, and demographic aspects of community features that made them vulnerable to flood impacts and possible natural resource changes $[18,93]$. This study has taken 11 criteria: population density, dependent and independent population, Kacha and Pacca houses, housing with water facilities, cultivated and uncultivated land, irrigated and un-irrigated area as discussed in Section 2.3.3. All the indicators were divided into sub-indicator and further process as discussed above in Section 3.1. The resulting map (Figure 9) shows that those communities living in the northern-western regions of the targeted area for the study are in high and very high vulnerable tracts, which covers an area of $395.98 \mathrm{~km}^{2}$ (Table 7). The high and very high socially and economically susceptible territories cover $24.85 \%$ of the overall area, separately. The socioeconomic vulnerability of these susceptible zones is because of a significant level of agricultural dependence Figure $6 a-d$, population density Figure $5 c$, Kacha housing units Figure 5e, and lack of freshwater sources availability Figure 6e. On the other side, the low and very low socially weak territories cover $216.64 \mathrm{~km}^{2}$ and $381.70 \mathrm{~km}^{2}$ (Table 7) respectively. These territories include the central-eastern as well as middle parts of the targeted study area. These areas have a better socioeconomic condition as compared to the other regions because of safe drinking water facilities, Pacca type of dwelling units, and the socioeconomic situation of the communities is better. The results indicated that agriculture dependency, population density, housing type of the specified area, and freshwater facilities are important parameters to determine the socioeconomic vulnerability of an area. Society or community with good socioeconomic conditions and easy and safe access to resources will have less chance of being impacted by hazards [22]. While a very high vulnerability category shows that communities with fragile infrastructure and inadequate access to basic 
services (health, drinking water, education, etc.) and insufficient livelihood, these elements increase the flood vulnerability in the study area. People are always trying to find their livelihood in a location where opportunity and hazard exist parallel [51]. Low-income people in rural areas tend to live in hazard-prone areas because they do not have the resources to live elsewhere [65]. In the rural districts, mostly the population is dependent directly or indirectly on agriculture to earn their livelihood in a location that combines opportunity and hazard [25]. The results agree with the previous studies $[1,8,30,65]$, which claims that flood disaster directly impacts agricultural lands, housing types of a specific area, and congested locality.

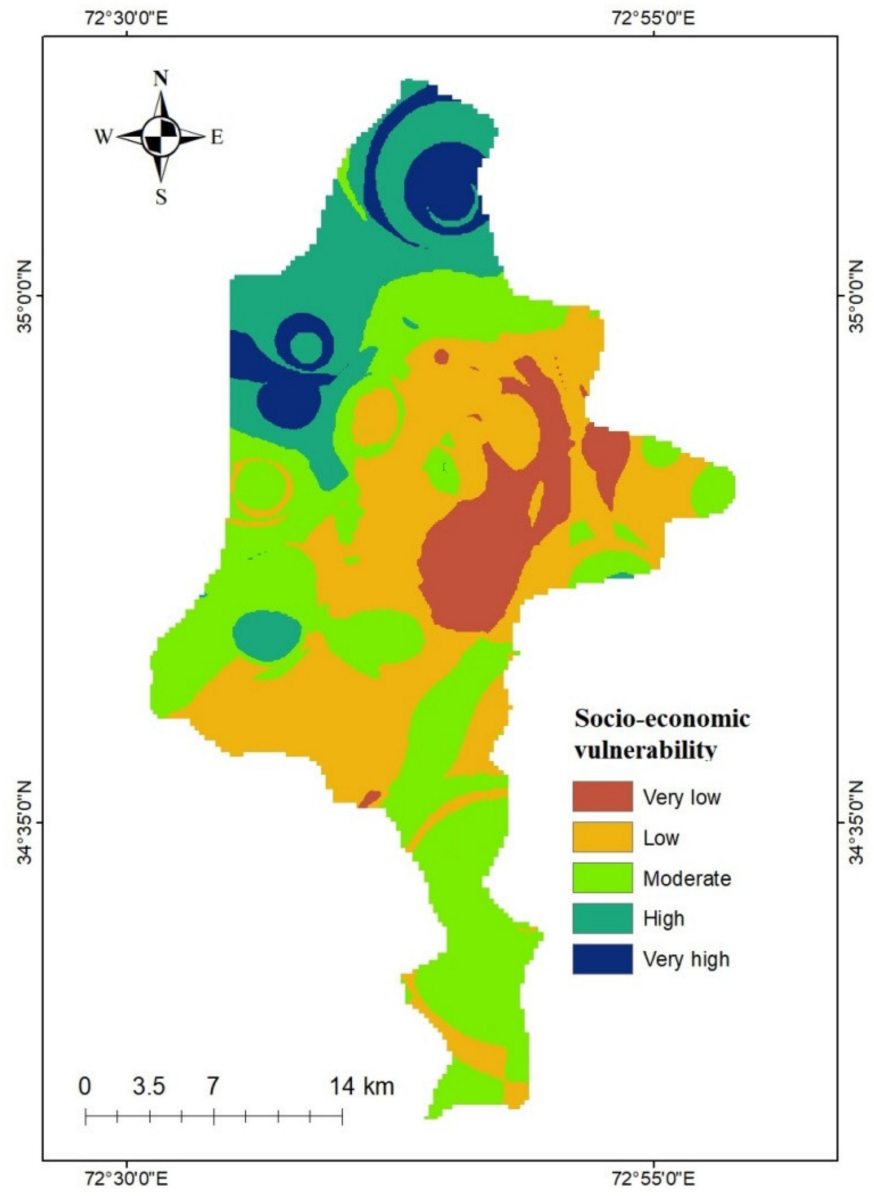

Figure 9. Socioeconomic vulnerability map displaying spatial pattern and the level of socioeconomic vulnerability to floods.

Table 7. The socioeconomic vulnerability of the study area after reclassification.

\begin{tabular}{cccc}
\hline Vulnerability Level & Area in $\mathbf{~ k m}^{\mathbf{2}}$ & Area $\%$ & Direction \\
\hline Very low & 216.64 & 13.60 & Central-eastern \\
Low & 381.70 & 23.95 & Central \\
Moderate & 599.76 & 37.63 & Western-southern \\
High & 246.80 & 15.49 & Northern-western \\
Very high & 149.18 & 9.36 & Northern-western \\
\hline
\end{tabular}

\subsection{Vulnerability without Incorporated Coping Capacity}

The indices' values of physical and social vulnerability were multiplied without integrating coping capacity to produce a flood vulnerability map of the target locality while classifying them into five vulnerable classes as shown in Figure 10. About 25\% of 
the area covered about $397 \mathrm{~km}^{2}$ comprising from high to the very high vulnerable level regions (Table 8). These regions spread from the western-middle to the northern part of the study regions due to the active channel's proximity, gentle slope, low elevation, population dependency, high precipitation, and population density.

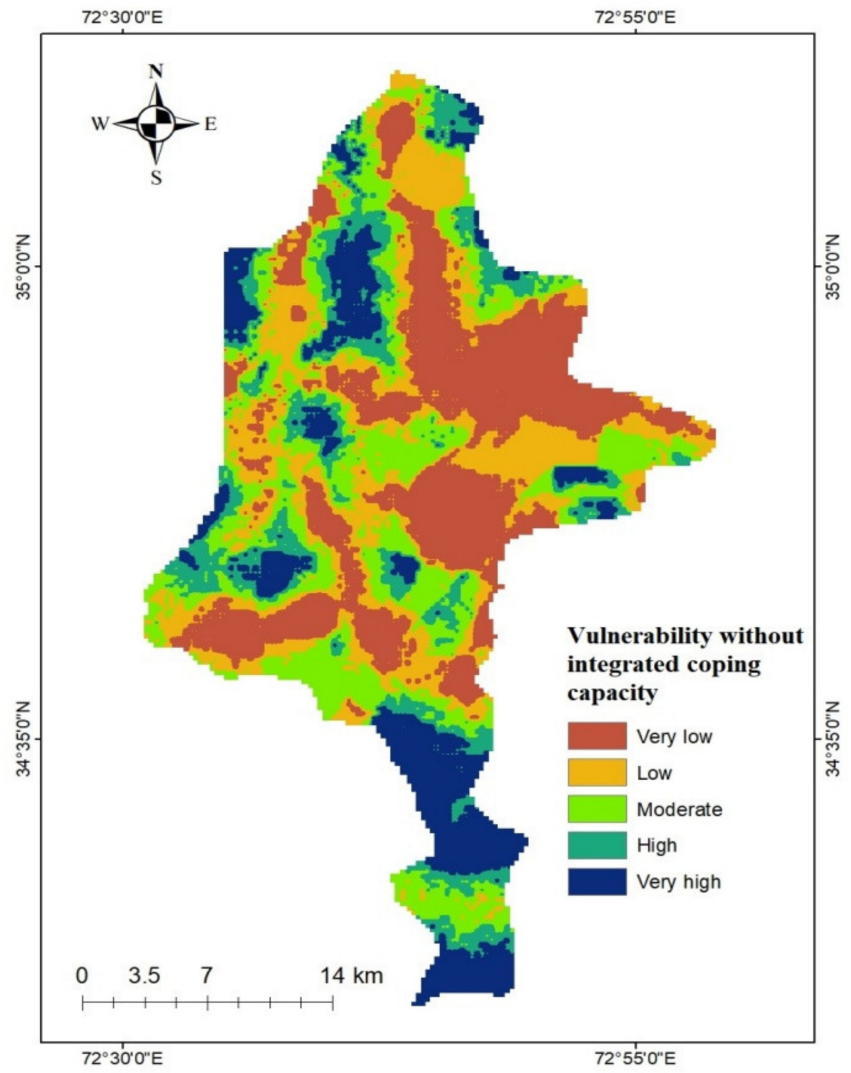

Figure 10. Vulnerability map without integrated coping capacity displaying spatial level and the degree to vulnerability to floods.

Table 8. Vulnerability of the study area; without integrated coping capacity after reclassification.

\begin{tabular}{cccc}
\hline Vulnerability Level & Area in $\mathbf{k m}^{\mathbf{2}}$ & Area $\mathbf{~}$ & Direction \\
\hline Very low & 447.45 & 28.06 & Eastern-central \\
Low & 351.27 & 22.03 & Central \\
Moderate & 399.44 & 25.05 & Central \\
High & 192.28 & 12.06 & Western-central \\
Very high & 204.49 & 12.83 & Northern \\
Total & 1594.48 & 100 & \\
\hline
\end{tabular}

While from eastern to central regions within the study area, about $50 \%\left(799 \mathrm{~km}^{2}\right)$ of the research area lays from very low to low vulnerable classes due to adequate drinking water facilities, well-structured housing units, minimum precipitation intensity, low population density, and safe agriculture lands. The remaining area $399.44 \mathrm{~km}^{2}$ comprises the moderate vulnerable area which covers $25.05 \%$. Most of these areas are in the middle part of the region in which dwelling units exist on a gentle slope, moderate elevation, and far away from rivers and streams. The results indicated that proximity to the active channel, gentle slope, agriculture and population dependency, population density are the main influencing factors that increase the vulnerability due to impacts of flood in District Shangla. The effectual mitigation strategies (awareness campaign about the occurring phenomenon, safe location for the construction) will reduce the sensitivity of the area to flood impacts. Slope 
and elevation are two important topographic factors that influence the flood generation mechanism [50,71].

\subsection{Vulnerability with Integrated Coping Capacity}

In flood vulnerability assessment, the integration of coping capacity is an important step towards actual vulnerability information. By incorporating coping capacity, physical and socioeconomic vulnerability indices were multiplied, divided by the coping capacity to generate a flood vulnerability map of the location-specific. After that, we categorized them into five vulnerable classes, as shown in Figure 11. The results demonstrated that $7 \%$ of the locality comprising from high to the very high vulnerable regions and these classes spread from the west to the southern part of the location specifics and covers about $103 \mathrm{~km}^{2}$ (Table 9). The generated output map is different from the map of vulnerability without coping capacity. The direction of vulnerable regions as well as the area under high to very high also changed from western-central and northern to western-southern in the top portion of the subject locality. The area under high to very high vulnerability was changed from $397 \mathrm{~km}^{2}$ to $103 \mathrm{~km}^{2}$. The change in results indicated that the middle and lower portion of the subject locality's is more vulnerable to floods because of low elevation, gentle slope, the communities are near to active channel of river and streams, exposure of agricultural lands to floods, and most of the communities are far away from health facilities. By contrast, very low to moderately vulnerable classes cover about $1490 \mathrm{~km}^{2}$ from central-northern towards southern-eastern. Comparing the integrated coping capacity with, with-out integrated coping capacity, the very low to moderate vulnerable region changed its direction from eastern-central to central-northern and southern directions. This changed in the direction occurred because of a reasonable literacy rate, and the communities have good socioeconomic conditions. Table 9 demonstrated that $93.57 \%$ $\left(1492 \mathrm{~km}^{2}\right)$ of the research area lying in very low to moderately vulnerable zones while the rest of the area $7 \%\left(103 \mathrm{~km}^{2}\right)$ enclosed high to very high vulnerable regions. The findings of the final vulnerability outcome are in agreement with Provincial Disaster Management Authority (PDMA) monsoon contingency report 2014 [48] and Nazeer et al. [35] where they demarcated those hotspot regions as we showed in Figure 11.

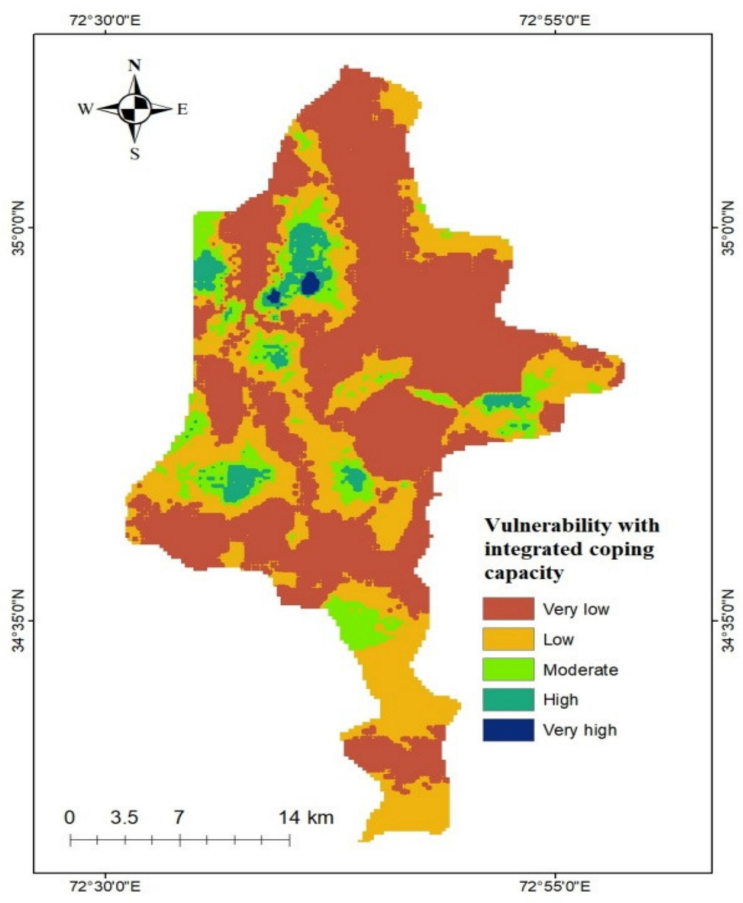

Figure 11. Integrated vulnerability map displaying spatial pattern and the degree of vulnerability to floods. 
Table 9. Vulnerability with an integrated coping capacity of the study area after reclassification.

\begin{tabular}{cccc}
\hline Vulnerability Level & Area in $\mathbf{~ k m}^{\mathbf{2}}$ & Area $\%$ & Directions \\
\hline Very low & 787.29 & 49.37 & Central-northern \\
Low & 542.52 & 34.02 & Central-southern \\
Moderate & 162.34 & 10.18 & Southern-eastern \\
High & 98.04 & 6.15 & Western-southern \\
Very high & 4.54 & 0.29 & Western \\
Total & 1594.48 & 100 & \\
\hline
\end{tabular}

\subsection{Validation of Vulnerability Evaluation}

There is no well-defined method that could validate the flood vulnerability mapping procedure. However, qualitative validation approaches were adopted by many researchers through field visits $[1,24]$. In our proposed study the subjective validation method was adopted in which a field visit was conducted in a different region in the study area where flood frequently occurs. For this purpose, personal discussion and observation with officials, specialists, and local people and their opinion and suggestion were viewed to measure and access our software's validity produced vulnerability maps and assessment results. We deeply observed those locations where the past flood occurred frequently and asked the local people about the severity and impact of floods. Afterward, we interviewed three types of respondents from the field consisting of specialists (who work on floods in the area), local people, and officials (concerned offices). A total of 29 out of 50 respondents were highly satisfied with our proposed results which are about $58 \%$. While $12(24 \%)$ respondents were satisfied, and the remaining $9(18 \%)$ of the respondents were not well pleased with the result obtained from flood vulnerability as showed in (Table 10). Furthermore, the vulnerability map with integrated coping capacity demonstrated that the western-southern portion of the subject locality was high to very high exposed regions, which were similar to the results obtained from the field in-depth observation. The field visit result also indicates that from very low to moderately vulnerable classes in the region is not that much affected by the past flood of 2010 and 2014.

Table 10. Validation of vulnerability assessment from the field.

\begin{tabular}{ccccc}
\hline \multirow{2}{*}{$\begin{array}{c}\text { Type of } \\
\text { Respondents }\end{array}$} & \multirow{2}{*}{$\begin{array}{c}\text { Total Number } \\
\text { of Respondents }\end{array}$} & \multicolumn{3}{c}{ Respondents Comments } \\
\cline { 3 - 5 } & 3 & Highly Assured & Assured & Not Assured \\
\hline Specialists & 2 & 1 & 0 & 1 \\
Officials & 45 & 26 & 1 & 0 \\
Local people & $50(100 \%)$ & $29(58 \%)$ & 11 & 8 \\
Total & & & $12(24 \%)$ & $9(18 \%)$ \\
\hline
\end{tabular}

\section{Conclusions and Policy Implications}

Climate-induced disasters, particularly floods in Pakistan, have caused noticeable destruction to Pakistan's economy both in terms of physical and human. The findings of this study will be helpful in the perspective of rural districts communities as the current developmental plans do not provide any details on local disaster risk reduction and assessment. In point of fact, the existence of district disaster management units in rural communities is non-existent and very nominal. Flood risk management in Pakistan requires to be proactive in contrast to the current reactive nature. In this regard, this research effort will be helpful for disaster management organizations and institutions in Pakistan for developing future disaster risk reduction strategies, particularly in rural flood-prone districts. The current study proposed a GIS-based multi-criteria approach for flood vulnerability portraying and analysis in the local administrative area of District Shangla, Khyber Pakhtunkhwa, Pakistan using a different type of geospatial data sets, census data as well as field data. To generate the thematic layers of selected metrics, in the state of three vulnerability constituents (physical, socioeconomic vulnerabilities, and coping capacity), 
geospatial techniques were used in the ArcMap settings to map the desired criteria. One of the best-known methods of MCDA known as AHP was implemented in the ArcMap (v10.2.2) setting to merge multi-criteria in the dimensional decision-making tactics. A subjective validation procedure was acquired, and the resulted vulnerability maps were validated through field visits, comprehensive introspection, and dialogue with local folks, related officials, and experts in the target locality. The proposed framework provides a proficient means to access the flood vulnerability at a local scale.

Inclusive flood vulnerability evaluation needs in-depth information on field condition, hydrologic statistics, detailed socioeconomic statistics, and features of flood protection structure so that GIS integrated multi-criteria mapping and assessment results could point out the impact of the flood on the definite area. For accurate and precise vulnerability mapping geospatial techniques need efficiency. Though, in poor countries, data collection for spatial decision-making techniques is very difficult and challenging. Our framework demonstrates the effectiveness of initiating comprehensive and precise vulnerability statistics by way of GIS-based multi-criteria assessment at the district level. The AHP has been very convenient for allocating weight to the particular criteria and alternatives. The results demonstrated that the high and very high vulnerability covers an area of $192.28 \mathrm{~km}^{2}$ $(12.06 \%)$ and $204.49 \mathrm{~km}^{2}(12.83 \%)$ from the western-central and northern directions of the study area, respectively. Furthermore, mapping real vulnerable information needs the incorporation of the coping capacity of the area in the vulnerability evaluation practices. While by incorporating the coping capacity the results completely change and show that high and very high vulnerable covers $98.04 \mathrm{~km}^{2}(6.15 \%)$ and $4.54 \mathrm{~km}^{2}(0.29 \%)$ from western-southern to western direction, respectively. Moreover, the justification of the results from the field improved the validity of this approach. The output of this study could be an outline for a preservationist, spatial data analysts, natural disaster and emergency managers, and disaster risk insurers for the selection of suitable datasets and processing techniques for producing flood disaster management information and helpful in flood mitigation tactics.

The results of this study are going along with some disadvantages. The selection of several criteria is required to process and map productive vulnerability evaluation. The used method operated in this research of vulnerability could be improved considerably following the inclusion of a variety of variables like hydrological soil groups, the geology of the area, poverty score, income level, family structure, construction materials in buildings, institutional capacity, etc. In addition, SRTM DEM of $30 \mathrm{~m}$ spatial resolution was used to generate the topographic maps. High spatial resolution landscape data of emerging technology such as Light Detection and Ranging (LiDAR) and DEM of 10m resolution could give better results. Moreover, in the proposed research, it was laborious to observe the convenient resource person for both the weighting exercise using AHP, as well as for the validations. Our study results were verified through subjective judgment based on factors analysis while quantitative judgment is a more inclusive approach that results in better accuracy. Future research can deal with the stated disadvantages. Without being the disadvantages, the defined strategy is still considered helpful for flood vulnerability mapping at the district level to support the district disaster management planner and other organizations to prepare disaster management plans for effective flood mitigation.

Supplementary Materials: The following are available online at https:/ / www.mdpi.com/2071-105 0/13/6/3126/s1, Figure S1: Stream network, roads and water bodies of District Shangla, Figure S2: diagram which show the flood hazard generation mechanism in the study area Table S1: Pairwise comparison matrix of physical vulnerability (preference matrix), Table S2: Pairwise comparison matrix of socioeconomic vulnerability (preference matrix), Table S3: Comparison matrix of coping capacity (Preference matrix), Table S4: Normalized matrix of physical vulnerability, Table S5: Normalized matrix of socioeconomic vulnerability, Table S6: Normalized matrix of coping capacity, Table S7: Consistency indices for a randomly generated matrix, Table S8: Calculation of Consistency Index (CI) of Physical vulnerability, Table S9: Calculation of Consistency Index (CI) of socioeconomic vulnerability, Table S10: Calculation of Consistency Index (CI) of Coping Capacity. 
Author Contributions: All authors contributed significantly to the preparation of this manuscript. Conceptualization, M.H. and J.Z.; methodology, M.H., M.T. and J.Z.; software, M.H. and M.T.; validation, M.H., A.A.S. and K.U.; formal analysis, M.H., M.T. and K.U.; investigation, M.H. and M.T.; resources, J.Z. and M.H.; data curation, M.H., M.T. and B.A.-S.; writing-original draft, M.H.; writing-review and editing, J.Z., A.A.S., K.U. and U.M.; visualization, M.H., M.T. and J.Z.; supervision, J.Z. and M.H.; project administration, J.Z., M.H. and M.T.; funding acquisition, J.Z. All authors have read and agreed to the published version of the manuscript.

Funding: This research is supported by the national key research and development program of China (2018YFC1508804); The Key Scientific and Technology Research and Development Program of Jilin Province (20180201033SF).

Institutional Review Board Statement: Not applicable.

Informed Consent Statement: Not applicable.

Data Availability Statement: The supporting used in this article can be accessed from these sources. The remote sensing data used in the article can be found on the websites (https:/ / earthexplorer.usgs. gov), (https:/ / www.usgs.gov/centers/eros/science/usgs-eros-archive-sentinel-2), The rainfall data can be found on the website of (https: / power.larc.nasa.gov/data-access-viewer/), The Census data can be found in (http:/ / www.pbs.gov.pk) on request, the other socioeconomic related data can found on (www.kpbos.gov.pk) and other data can be found in Supplementary Materials.

Acknowledgments: We would like to thank District Health, Education and Agriculture departments, Shangla for providing us the relevant data and United States Geological survey (USGS) for Sentinel 2 and ASTER DEM images.

Conflicts of Interest: The authors declare no conflict of interest.

\section{References}

1. Hoque, M.A.A.; Tasfia, S.; Ahmed, N.; Pradhan, B. Assessing Spatial Flood Vulnerability at Kalapara Upazila in Bangladesh Using an Analytic Hierarchy Process. Sensors 2019, 19, 1302. [CrossRef]

2. Wilhelm, B.; Ballesteros-Canovas, J.A.; Macdonald, N.; Wilhelm, B.; Toonen, W.H.J.; Baker, V.; Barriendos, M.; Brauer, A.; Corella, J.P.; Denniston, R.; et al. Interpreting Historical, Botanical, and Geological Evidence to Aid Preparations for Future Floods. Wiley Interdiscip. Rev. Water 2018, 6, e1318. [CrossRef]

3. Wahlstrom, M.; Guha-Sapir, D. The Human Cost of Weather-Related Disasters 1995-2015; Center for Research on the Epidemiology of Disasters Cred: Geneva, Switzerland, 2015.

4. Busico, G.; Giuditta, E.; Kazakis, N. A Hybrid GIS and AHP Approach for Modelling Actual and Future Forest Fire Risk Under Climate Change. Sustainability 2019, 11, 7166. [CrossRef]

5. Atta-ur-Rahman; Khan, A.N. Analysis of 2010-Flood Causes, Nature and Magnitude in the Khyber Pakhtunkhwa, Pakistan. Nat. Hazards 2013, 66, 887-904. [CrossRef]

6. Aldous, A.; Fitzsimons, J.; Richter, B.; Bach, L. Droughts, Floods and Freshwater Ecosystems: Evaluating Climate Change Impacts and Developing Adaptation Strategies. Mar. Freshw. Res. 2011, 62, 223-231. [CrossRef]

7. Mahapatra, M.; Ramakrishnan, R.; Rajawat, A.S. Coastal Vulnerability Assessment Using Analytical Hierarchical Process for South Gujarat Coast, India. Nat. Hazards 2015, 76, 139-159. [CrossRef]

8. Shah, A.A.; Ye, J.; Abid, M.; Khan, J.; Amir, S.M. Flood Hazards: Household Vulnerability and Resilience in Disaster-Prone Districts of Khyber Pakhtunkhwa Province, Pakistan. Nat. Hazards 2018, 93, 147-165. [CrossRef]

9. Shah, A.A.; Ye, J.; Shaw, R.; Ullah, R.; Ali, M. Factors Affecting Flood-Induced Household Vulnerability and Health Risks in Pakistan: The Case of Khyber Pakhtunkhwa (KP) Province. Int. J. Disaster Risk Reduct. 2020, 42, 101341. [CrossRef]

10. Shah, A.A.; Ye, J.; Pan, L.; Ullah, R.; Shah, S.I.A.; Fahad, S.; Naz, S. Schools' Flood Emergency Preparedness in Khyber Pakhtunkhwa Province, Pakistan. Int. J. Disaster Risk Sci. 2018, 9, 181-194. [CrossRef]

11. Shah, A.A.; Ye, J.; Abid, M.; Ullah, R. Determinants of Flood Risk Mitigation Strategies at Household Level: A Case of Khyber Pakhtunkhwa (KP) Province, Pakistan. Nat. Hazards 2017, 1, 415-430. [CrossRef]

12. Bodoque, J.M.; Ballesteros-Cánovas, J.A.; Stoffel, M. An Application-Oriented Protocol for Flood Frequency Analysis Based on Botanical Evidence. J. Hydrol. 2020, 590, 125242. [CrossRef]

13. Ballesteros-Canovas, J.A.; Koul, T.; Bashir, A.; Maria, J. Recent Flood Hazards in Kashmir Put into Context with Millennium-Long Historical and Tree-Ring Records. Sci. Total Environ. 2020, 722, 137875. [CrossRef]

14. Ballesteros-Canovas, J.A.; Quesada-Román, A.; Granados-Bolaños, S. Dendrogeomorphic Reconstruction of Floods in a Dynamic Tropical River. Geomorphology 2020, 359, 107133. [CrossRef]

15. Allen, S.K.; Ballesteros-Canovas, J.; Randhaw, S.S.; Singha, A.K.; Huggel, C.; Stoffel, M. Translating the concept of climate risk into an assessment framework to inform adaptation Planning: Insights from a pilot study of flood risk in Himachal Pradesh, Northern India. Environ. Sci. Policy 2018, 87, 1-10. [CrossRef] 
16. Rica, C.; Quesada-Román, A.; Villalobos-Chacón, A. Flash Flood Impacts of Hurricane Otto and Hydrometeorological Risk Mapping Flash Flood Impacts of Hurricane Otto and Hydrometeorological Risk Mapping in Costa Rica. Geogr. Tidsskr. Dan. J. Geogr. 2020. [CrossRef]

17. Miranda, F.N.; Ferreira, T.M. A Simplified Approach for Flood Vulnerability Assessment of Historic Sites. Nat. Hazards 2019, 96, 713-730. [CrossRef]

18. Jhan, H.; Ballinger, R.; Jaleel, A.; Ting, K. Development and Application of a Socioeconomic Vulnerability Indicator Framework (SVIF) for Local Climate Change Adaptation in Taiwan. Sustainability 2020, 12, 1585. [CrossRef]

19. Birkmann, J. Measuring Vulnerability to Natural Hazards; Alexander, D., Handmer, J., McBean, G., Eds.; United Nation University Press: Tokyo, Japan, 2013; pp. 9-699. ISBN 9789280812022.

20. Bronkhorst, V.B.; Dani, S.; Forni, M.; Ghesquiere, F.; Kahandawa, S.; Kazi, S.; Khan, H.; Pokhrel, A.; Singh, D.; Tshering, D.; et al Disaster Risk Management in South Asia: A Regional Overview; World Bank: Washington, DC, USA, 2012.

21. Rana, I.A.; Routray, J.K. Multidimensional Model for Vulnerability Assessment of Urban Flooding: An Empirical Study in Pakistan. Int. J. Disaster Risk Sci. 2018, 9, 359-375. [CrossRef]

22. Fernandez, P.; Mourato, S.; Moreira, M. Social Vulnerability Assessment of Flood Risk Using GIS-Based Multicriteria Decision Analysis. A Case Study of Vila Nova de Gaia. Geomat. Nat. Hazards Risk 2016, 7, 1367-1389. [CrossRef]

23. Etkin, D. Disaster Theory: Hazard, Vulnerability, and Resilience; Scott, S., LaFleur, M., Purushothaman, V., Eds.; ButterworthHeinemann (Elsevier): Kidlington, UK; Oxford, UK, 2016; ISBN 9780128002278.

24. Roy, D.C.; Blaschke, T. Spatial Vulnerability Assessment of Floods in the Coastal Regions of Bangladesh. Geomat. Nat. Hazards Risk 2015, 6, 21-44. [CrossRef]

25. Jamshed, A.; Rana, I.A.; Birkmann, J.; Nadeem, O. Changes in Vulnerability and Response Capacities of Rural Communities After Extreme Events: Case of Major Floods of 2010 and 2014 in Pakistan. J. Extrem. Events 2017, 4, 1750013. [CrossRef]

26. de Andrade, M.M.N.; Szlafsztein, C.F. Vulnerability Assessment Including Tangible and Intangible Components in the Index Composition: An Amazon Case Study of Flooding and Flash Flooding. Sci. Total Environ. 2018, 630, 903-912. [CrossRef]

27. Lummen, N.S.; Yamada, F. Implementation of an Integrated Vulnerability and Risk Assessment Model. Nat. Hazards 2014, 73, 1085-1117. [CrossRef]

28. Menoni, S.; Molinari, D.; Parker, D.; Ballio, F.; Tapsell, S. Assessing Multifaceted Vulnerability and Resilience in Order to Design Risk-Mitigation Strategies. Nat. Hazards 2012, 64, 2057-2082. [CrossRef]

29. Rimba, A.; Setiawati, M.; Sambah, A.; Miura, F. Physical Flood Vulnerability Mapping Applying Geospatial Techniques in Okazaki City, Aichi Prefecture, Japan. Urban Sci. 2017, 1, 7. [CrossRef]

30. Vojtek, M.; Vojteková, J. Flood Susceptibility Mapping on a National Scale in Slovakia Using the Analytical Hierarchy Process. Water 2019, 11, 364. [CrossRef]

31. Shivaprasad Sharma, S.V.; Roy, P.S.; Chakravarthi, V.; Srinivasa Rao, G. Flood Risk Assessment Using Multi-Criteria Analysis: A Case Study from Kopili River Basin, Assam, India. Geomat. Nat. Hazards Risk 2018, 9, 79-93. [CrossRef]

32. Scheuer, S.; Haase, D.; Meyer, V. Exploring Multicriteria Flood Vulnerability by Integrating Economic, Social and Ecological Dimensions of Flood Risk and Coping Capacity: From a Starting Point View towards an End Point View of Vulnerability. Nat. Hazards 2011, 58, 731-751. [CrossRef]

33. Wang, Y.; Li, Z.; Tang, Z.; Zeng, G. A GIS-Based Spatial Multi-Criteria Approach for Flood Risk Assessment in the Dongting Lake Region, Hunan, Central China. Water Resour. Manag. 2011, 25, 3465-3484. [CrossRef]

34. Xiong, J.; Li, J.; Cheng, W.; Wang, N.; Guo, L. A GIS-Based Support Vector Machine Model for Flash Flood Vulnerability Assessment and Mapping in China. ISPRS Int. J. Geo-Inf. 2019, 8, 297. [CrossRef]

35. Nazeer, M.; Bork, H.R. Flood Vulnerability Assessment through Different Methodological Approaches in the Context of NorthWest Khyber Pakhtunkhwa, Pakistan. Sustainability 2019, 11, 6695. [CrossRef]

36. Chakraborty, A.; Joshi, P.K. Mapping Disaster Vulnerability in India Using Analytical Hierarchy Process. Geomat. Nat. Hazards Risk 2016, 5705, 308-325. [CrossRef]

37. Aroca-Jimenez, E.; Bodoque, J.M.; Antonio Garcia, J.; Diez-Herrero, A. Construction of an Integrated Social Vulnerability Index in Urban Areas Prone to Flash Flooding. Nat. Hazards Earth Syst. Sci. 2017, 17, 1541-1557. [CrossRef]

38. Fekete, A.; Damm, M.; Birkmann, J. Scales as a Challenge for Vulnerability Assessment. Nat. Hazards 2010, 55, 729-747. [CrossRef]

39. Zeleňáková, M.; Gaňová, L.; Purcz, P.; Satrapa, L. Methodology of Flood Risk Assessment from Flash Floods Based on Hazard and Vulnerability of the River Basin. Nat. Hazards 2015, 79, 2055-2071. [CrossRef]

40. UNDRR. Global Assessment Report on Disaster Risk Reduction; UNDRR: Geneva, Switzerland, 2019.

41. Cutter, S.L.; Barnes, L.; Berry, M.; Burton, C.; Evans, E.; Tate, E.; Webb, J. A Place-Based Model for Understanding Community Resilience to Natural Disasters. Glob. Environ. Chang. 2008, 18, 598-606. [CrossRef]

42. UNISDR. UNISDR Terminology on Disaster Risk Reduction; UNISDR: Geneva, Switzerland, 2009.

43. Radhakrishnan, M.; Nguyen, H.Q.; Gersonius, B.; Pathirana, A.; Vinh, K.Q.; Ashley, R.M.; Zevenbergen, C. Coping Capacities for Improving Adaptation Pathways for Flood Protection in Can Tho, Vietnam. Clim. Chang. 2018, 149, 29-41. [CrossRef]

44. Rana, I.A.; Routray, J.K. Integrated Methodology for Flood Risk Assessment and Application in Urban Communities of Pakistan. Nat. Hazards 2018, 91, 239-266. [CrossRef]

45. GOP. Government of Pakistan Ministry of Water Resources: Annual Flood Report 2017; GOP: Islamabad, Pakistan, 2017. 
46. Ullah, F.; Saqib, S.E.; Ahmad, M.; Ali, M. Flood Risk Perception and Its Determinants among Rural Households in Two Communities in Khyber Pakhtunkhwa, Pakistan. Nat. Hazards 2020. [CrossRef]

47. Atta-ur-Rahman; Khan, A.N. Analysis of Flood Causes and Associated Socio-Economic Damages in the Hindukush Region. Nat. Hazards 2011, 59, 1239-1260. [CrossRef]

48. PDMA. Monsoon Contingency Plan; Government of Khyber Pakhtunkhwa: Peshawar, Pakistan, 2014. Available online: https: / / www.pdma.gov.pk (accessed on 23 October 2020).

49. Gaurav, K.; Sinha, R.; Panda, P.K. The Indus Flood of 2010 in Pakistan: A Perspective Analysis Using Remote Sensing Data. Nat. Hazards 2011, 59, 1815-1826. [CrossRef]

50. Moazzam, M.F.U.; Vansarochana, A.; Rahman, A.U. Analysis of Flood Susceptibility and Zonation for Risk Management Using Frequency Ratio Model in District Charsadda, Pakistan. Int. J. Environ. Geoinform. 2018, 5, 140-153. [CrossRef]

51. Jamshed, A.; Rana, I.A.; Mirza, U.M.; Birkmann, J. Assessing Relationship between Vulnerability and Capacity: An Empirical Study on Rural Flooding in Pakistan. Int. J. Disaster Risk Reduct. 2019, 36, 101109. [CrossRef]

52. Malczewski, J. GIS-Based Multicriteria Decision Analysis: A Survey of the Literature. Int. J. Geogr. Inf. Sci. 2006, 20, 703-726. [CrossRef]

53. García-Soriano, D.; Quesada-Román, A.; Zamorano-Orozco, J.J. Geomorphological Hazards Susceptibility in High-Density Urban Areas: A Case Study of Mexico City. J. S. Am. Earth Sci. 2020, 102, 102667. [CrossRef]

54. Ouma, Y.O.; Tateishi, R. Urban Flood Vulnerability and Risk Mapping Using Integrated Multi-Parametric AHP and GIS: Methodological Overview and Case Study Assessment. Water 2014, 6, 1515-1545. [CrossRef]

55. Abdelkarim, A.; Al-Alola, S.S.; Alogayell, H.M.; Mohamed, S.A.; Alkadi, I.I.; Ismail, I.Y. Integration of GIS-Based Multicriteria Decision Analysis and Analytic Hierarchy Process to Assess Flood Hazard on the Al-Shamal Train Pathway in Al-Qurayyat Region, Kingdom of Saudi Arabia. Water 2020, 12, 1702. [CrossRef]

56. Samanta, S.; Koloa, C.; Pal, D.K.; Palsamanta, B. Flood Risk Analysis in Lower Part of Markham River Based on Multi-Criteria Decision Approach (MCDA). Hydrology 2016, 3, 29. [CrossRef]

57. Wu, Y.; Zhong, P.; Zhang, Y.; Xu, B.; Ma, B.; Yan, K. Integrated Flood Risk Assessment and Zonation Method: A Case Study in Huaihe River Basin, China. Nat. Hazards 2015, 78, 635-651. [CrossRef]

58. Bisht, S.; Chaudhry, S.; Sharma, S.; Soni, S. Remote Sensing Applications: Society and Environment Assessment of Flash Flood Vulnerability Zonation through Geospatial Technique in High Altitude Himalayan Watershed, Himachal Pradesh India. Remote Sens. Appl. Soc. Environ. 2018, 12, 35-47. [CrossRef]

59. Ahmad, S.; Israr, M.; Ahmad, R.; Bilal, H.; Hayat, W. Assessment of River Shahpur for Flood Risk in Northern Pakistan. Civ. Environ. Res. 2015, 7, 20-27.

60. Rahman, G.; Rahman, A.; Ullah, S.; Miandad, M.; Collins, A.E. Spatial Analysis of Landslide Susceptibility Using Failure Rate Approach in the Hindu Kush Region, Pakistan. J. Earth Syst. Sci. 2019, 128, 1-16. [CrossRef]

61. Rahman, G.; Collins, A.E. Geospatial Analysis of Landslide Susceptibility and Zonation in Shahpur Valley, Eastern Hindu Kush Using Frequency Ratio Model. Pak. Acad. Sci. 2017, 54, 149-163.

62. ERRA. Report of Earthquake Reconstruction \& Rehabilitation Authority Government of Pakistan Provincial Earthquake Reconstruction $\mathcal{E}$ Rehabilitation Agency Government of NWFP; ERRA: Islamabad, Pakistan, 2007. Available online: http:/ /www.erra.gov.pk (accessed on 25 October 2020).

63. Khan, N.; Shah, S.J.; Rauf, T.; Zada, M.; Yukun, C.; Harbi, J. Socioeconomic Impacts of the Billion Trees Afforestation Program in Khyber Pakhtunkhwa Province (KPK), Pakistan. Forests 2019, 10, 703. [CrossRef]

64. UNDP. District Disaster Risk Management Plan; UNDP: Islamabad, Pakistan, 2007. Available online: http://www.undp.org.pk (accessed on 7 November 2020).

65. Khan, F.A.; Salman, A. A Simple Human Vulnerability Index to Climate Change Hazards for Pakistan. Int. J. Disaster Risk Sci. 2012, 3, 163-176. [CrossRef]

66. Chaudhry, Q.U.Z. Climate Change Profile of Pakistan; Asian Development Bank: Mandaluyong City, Philippines, 2017.

67. Rincón, D.; Khan, U.T.; Armenakis, C. Flood Risk Mapping Using GIS and Multi-Criteria Analysis: A Greater Toronto Area Case Study. Geosciences 2018, 8, 275. [CrossRef]

68. Mojaddadi, H.; Pradhan, B.; Nampak, H.; Ahmad, N.; Ghazali, A.H. Ensemble Machine-Learning-Based Geospatial Approach for Flood Risk Assessment Using Multi-Sensor Remote-Sensing Data and GIS. Geomat. Nat. Hazards Risk 2017, 8, 1080-1102. [CrossRef]

69. Dewan, A.M. Floods in a Megacity: Geospatial Techniques in Assessing Hazards, Risk and Vulnerability; Springer: Dordrecht, The Netherlands, 2013; ISBN 9789400758742.

70. Papathoma-Köhle, M.; Kappes, M.; Keiler, M.; Glade, T. Physical Vulnerability Assessment for Alpine Hazards: State of the Art and Future Needs. Nat. Hazards 2011, 58, 645-680. [CrossRef]

71. Ullah, K.; Zhang, J. GIS-Based Flood Hazard Mapping Using Relative Frequency Ratio Method: A Case Study of Panjkora River Basin, Eastern Hindu Kush. PLoS ONE 2020, 15, e229153. [CrossRef]

72. Kourgialas, N.N.; Karatzas, G.P.; Kourgialas, N.N.; Karatzas, G.P. Flood Management and a GIS Modelling Method to Assess Flood-Hazard Areas-A Case Study Flood Management and a GIS Modelling Method to Assess Flood-Hazard Areas-A Case Study. Hydrol. Sci. J. 2011, 6667, 212-225. [CrossRef] 
73. Yang, W.; Xu, K.; Lian, J.; Ma, C.; Bin, L. Integrated Flood Vulnerability Assessment Approach Based on TOPSIS and Shannon Entropy Methods. Ecol. Indic. 2018, 89, 269-280. [CrossRef]

74. Ullah, S.; Farooq, M.; Shafique, M.; Siyab, M.A.; Kareem, F.; Dees, M. Spatial Assessment of Forest Cover and Land-Use Changes in the Hindu-Kush Mountain Ranges of Northern Pakistan. J. Mt. Sci. 2016, 13, 1229-1237. [CrossRef]

75. Ryu, S.; Song, J.J.; Kim, Y.; Jung, S.H.; Do, Y.; Lee, G.W. Spatial Interpolation of Gauge Measured Rainfall Using Compressed Sensing. Asia-Pac. J. Atmos. Sci. 2020. [CrossRef]

76. Manandhar, R.; Odeh, I.O.; Ancev, T. Improving the Accuracy of Land Use and Land Cover Classification of Landsat Data Using Post-Classification Enhancement. Remote Sens. 2009, 10, 330-344. [CrossRef]

77. Ghebrezgabher, M.G.; Yang, T.; Yang, X.; Wang, X.; Khan, M. Extracting and Analyzing Forest and Woodland Cover Change in Eritrea Based on Landsat Data Using Supervised Classification. Egypt. J. Remote Sens. Space Sci. 2016, 19, 37-47. [CrossRef]

78. Kumar, P.; Rani, M.; Pandey, P.C.; Majumdar, A.; Nathawat, M.S. Monitoring of Deforestation and Forest Degradation Using Remote Sensing and GIS: A Case Study of Ranchi in Jharkhand (India). Rep. Opin. 2010, 2, 14-20.

79. Masuya, A.; Dewan, A.; Corner, R.J. Population Evacuation: Evaluating Spatial Distribution of Flood Shelters and Vulnerable Residential Units in Dhaka with Geographic Information Systems. Nat. Hazards 2015, 78, 1859-1882. [CrossRef]

80. Mizen, A.; Fry, R.; Rodgers, S. GIS-Modelled Built-Environment Exposures Reflecting Daily Mobility for Applications in Child Health Research. Int. J. Health Geogr. 2020, 19, 1-13. [CrossRef] [PubMed]

81. Zakour, M.J.; Gillespie, D.F. Community Disaster Vulnerability; Springer: New York, NY, USA, 2013; ISBN 9781461457367.

82. FAO International Workshop on Policy Options for Socioeconomic Vulnerability Analysis: Conflict Analysis and LongTerm Development Programmes and Strategies. 2003. Available online: http://www.fao.org.3/a-ae517e.pdf (accessed on 20 November 2020).

83. Kienberger, S.; Blaschke, T.; Zaidi, R.Z. A Framework for Spatio-Temporal Scales and Concepts from Different Disciplines: The 'Vulnerability Cube'. Nat. Hazards 2013, 68, 1343-1369. [CrossRef]

84. Sun, R.; An, D.; Lu, W.; Shi, Y.; Wang, L.; Zhang, C.; Zhang, P. Impacts of a Flash Flood on Drinking Water Quality: Case Study of Areas Most Affected by the 2012 Beijing Flood. Heliyon 2016. [CrossRef] [PubMed]

85. Neumayer, E.; Plümper, T. The Gendered Nature of Natural Disasters: The Impact of Catastrophic Events on the Gender Gap in Life Expectancy, 1981-2002. Ann. Assoc. Am. Geogr. 2007, 97, 551-566. [CrossRef]

86. Annas, S.; Rais, Z. K-Means and GIS for Mapping Natural Disaster Prone Areas in Indonesia. In Proceedings of the The 7th Mathematics, Science, and Computer Science Education International Seminar (MSCEIS), Bandung, Indonesia, 30 December 2020; pp. 1-7.

87. Feloni, E. Flood Vulnerability Assessment Using a GIS-Based Multi-Criteria Approach-The Case of Attica Region. J. Flood Risk Manag. 2020, 13, e12563. [CrossRef]

88. SAATY, R.W. The Anslytic Hierarchy Process-What and How It Is Used. Math. Model. 1987, 9, 161-176. [CrossRef]

89. Kazuva, E.; Zhang, J.; Tong, Z.; Si, A.; Na, L. The DPSIR Model for Environmental Risk Assessment of Municipal Solid Waste in Dar Es Salaam City, Tanzania. Int. J. Environ. Res. Public Health 2018, 15, 1692. [CrossRef] [PubMed]

90. Le Cozannet, G.; Garcin, M.; Bulteau, T.; Mirgon, C.; Yates, M.L.; Méndez, M.; Baills, A.; Idier, D.; Oliveros, C. An AHP-Derived Method for Mapping the Physical Vulnerability of Coastal Areas at Regional Scales. Nat. Hazards Earth Syst. Sci. 2013, 13, 1209-1227. [CrossRef]

91. Chen, W.; Han, H.; Huang, B.; Huang, Q.; Fu, X. Variable-Weighted Linear Combination Model for Landslide Susceptibility Mapping: Case Study in the Shennongiia Forestry District, China. ISPRS Int. J. Geo-Inf. 2017, 6, 347. [CrossRef]

92. Al-Hanbali, A.; Alsaaideh, B.; Kondoh, A. Using GIS-Based Weighted Linear Combination Analysis and Remote Sensing Techniques to Select Optimum Solid Waste Disposal Sites within Mafraq City, Jordan. J. Geogr. Inf. Syst. 2011, 3, 267-278. [CrossRef]

93. Debortoli, N.S.; Camarinha, P.I.M.; Marengo, J.A.; Rodrigues, R.R. An Index of Brazil's Vulnerability to Expected Increases in Natural Flash Flooding and Landslide Disasters in the Context of Climate Change. Nat. Hazards 2017, 86, 557-582. [CrossRef] 